\title{
EL SECTOR TEXTIL Y EL COMERCIO EXTERIOR DE MALLORCA EN UNA ÉPOCA DE CAMBIO $(1630 / 1720)^{1}$
}

por

\author{
ANDREU BIBILONI
}

Universidad de Sevilla.

RESUMEN: A lo largo del siglo XVTI la economia mallorquina conocerá un profundo cambio estructural identificado, especialmente, en su capacidad exportadora. La tradicional begemonia de la manufactura de lana en las exportaciones se quiebra para dar paso a la supremaía del aceite. Los paños de baja calidad experimentan un descenso acelerado que les lleva a desaparecer de las exportaciones mientras que desde 1680 se disparan las compras de tejidos y fibras de lino y algodón asi como de tintes. La balanza comercial se deteriora cuando el aceite, acompañado coyunturalmente por las extraciones de aguardiente, no puede compensar la fiebre importadora. Los productores textiles reacionan con la producción de telas de lino y algodón. Sin embargo no parecen ser competitivos en el mercado exterior y canalizan su producto bacia el mercado interno. La vinculación con el mercado francés, las nuevas medidas proteccionistas de la segunda década del siglo XVTII y la irrupción del tráfico comercial ligada a la peste de Marsella abren un nuevo tipo de relaciones aún por estudiar.

PAlABRAS ClaAvE: Manufactura textil. Mallorca. Comercio. Siglos XVI y XVII. Consumo.

ABSTRACT: Durinf the seventeenth century, the economy of Mallorca experienced a deep structural change associated especially with its export capacity. The traditional begemony of wool manifacture was broken, giving way to the supremacy of olive oil. Low-quality clothes undervent a faster decrease, leading them ultimately to disappear from exports, while from 1680 the purchase of linen and cotton fibres and of dyes took off. The balance of trade deteriorated when olive oil exports, together with extractions of aguardiente, failed to compensate for the import fever. Textile manufacturers responded by producing linen and cotton

1 Los archivos consultados para este artículo son: Archivo General de Simancas (AGS), Arxiu de la Corona d'Aragó (ACA) y A rxiu del Regne de Mallorca (ARM). En lo sucesivo se citarán por las siglas correspondientes. Este trabajo se ha enriquecido con las sugerencias de A.L. López Martínez, I. Lobato Franco y J. Pons Pons, así como del continuo intercambio de impresiones mantenido con M.J. Deyá Bauzá. Del mismo modo, quiero agradecer a G. Jover permitirme el acceso a su tesis doctoral, aún inédita, y sus valiosas reflexiones.

Hipatuia, LJX/3, núm. 203 (199) 897-224 
clothes. However, they did not seem to be competitive in the foreing market and channeled their production towards the domestic market. Their links with the French market, the new protectionist measures of the second decade of the eighteenth century and the interruption of commercial traffic connected with the plague on Marseilles, open up a new field of relationsbips that remain to be studied.

KeY worbs: Textil manufacture. Mallorca. Trade. 17th-18th Centuries. Consumption.

Estas páginas pretenden acercarse, con cautela, a un tema muy tratado por la historiografia europea pero que en el caso de Mallorca ha tenido un escaso eco. Se trata de los cambios en el consumo textil producidos durante el periodo $1630 \mathrm{a}$ 1716/1720. La cautela se debe, fundamentalmente, a que esta aproximación se hace a partir de datos comerciales y no de producción. El uso de este indicador indirecto condicionará muchas, si no la mayoría, de las conclusiones a las que se pueda llegar, pero en cualquier caso permite exponer una serie de reflexiones que, tal vez, sirvan como punto de apoyo para futuras investigaciones.

El objetivo central de este estudio es observar y, en la medida de lo posible, explicar los cambios que afectan a los intercambios textiles de Mallorca durante casi un siglo. Unos años en los que se produce un importante cambio estructural que afecta a diferentes sectores de su economía y que no han sido calibrados y, mucho menos, analizados en el largo plazo. Unos años, en definitiva, que por lo que respecta al sector textil se definen por la paulatina decadencia de la producción/exportación vinculada al subsector lanero y el espectacular aumento de la importación de telas de lino y algodón. A partir de este esquema, aunque aquí no se pueda responder a todas las preguntas, es preciso plantear: 1) ¿cómo reaccionan los productores insulares ante el doble efecto de la avalancha importadora de algodones y lienzos, por una parte, y el descenso de la exportación de manufacturas de lana por otra?; 2) ¿qué respuestas se dan a la creciente importación de fibras de lino y algodón, así como de materias primas tintóreas?; 3) ¿pudo desembocar este proceso en el impulso de una industria sustitutiva de las importaciones?; 4) ¿por qué se interrumpe este proceso, fuera el que fuera, durante el primer tercio del siglo XVIII?; y 5) ¿cómo afectan estos cambios a la balanza comercial?.

Las documentación examinada se centra en fuentes de carácter fiscal ligadas al comercio. El grueso de la información procede de los libros del Victigal de Mar y Col.legi de la Mercaderia que recogen las entradas y salidas del puerto de la Ciutat de Mallorca (desde principios del siglo XVIII Palma) de barcos, mercancías y sus valoraciones, el nombre de los cargadores (en ocasiones su origen y ocupación) y los transportistas ${ }^{2}$. Como complemento fundamental, aunque no

2 Se dispone de entradas y salidas de 28 años reflejando el tráfico de unos 8.000 barcos. ARM, Arxiu Històric (=AH), legajos 786, 1358, 1359, 1361-64, 1366-70, 1377-9, 1381, 1384,

Hilipania, LIX/3, núm. 203 (1999) 897-924 
el único ${ }^{3}$, también se han analizado los libros correspondientes al Derecho de 10 por ciento y conirabando que por sus propias características - ya que grava las mercancias fabricadas y o transportadas por enemigos a la corona española-, resulta muy útil para contabilizar el tráfico de telas ${ }^{4}$.

La cronología propuesta, 1630-1720, constituye un período muy irregular salpicado por constantes inflexiones que afectan a todos los órdenes de la vida ${ }^{5}$. Entre las principales manifestaciones que determinan la evolución económica de la isla a lo largo del seiscientos destacan:

1. La década de los treinta coincide con la plenitud de una grave contracción que combina el descenso demográfico con reiteradas crisis de subsistencias como principales manifestaciones que se hacen extensivas a toda la primera mitad del siglo y se prolongan hasta bien entrada la década de los sesenta ". La decadencia de Mallorca parece incuestionable aunque todavía no se haya medido en toda su extensión. Al tiempo, en la primera mitad del siglo XVII se consolida la transición de una economía de exportación textil lanera hacia otra de exportación agrícola asentada en los excedentes de aceite.

2. Los años cincuenta añaden un doble componente con tintes especialmente negativos. Desde el punto de vista financiero, el fracaso de las reformas

1518-21, 1532, 1536, 1544, 1545, 5545, Còdex 152 y Reial Patrimoni (=RP) 2143 correspondiente a los años 1635-36, 1656-57, 1660-61, 1662-1663, 1667-68, 1671-1673, 1676-77, 1678-79, $1680-1682,1683-1685,1687-1691,1697-1704,1707-08,1715-1718$. Debido a criterios metodológicos de cuantificación (no reflejan las valoraciones) se ha prescindido de los registros de los años 1663, 1668,1672, 1682 y 1717 de forma que el estudio se centra en el movimiento de unos 6500 barcos. Esta información ha sido debidamente completada con la documentación notarial analizada en PoNs PONS, Jerònia, Companyies $i$ mercat assegurador a Mallorra (1650-1715), Vol. II, págs. 602-779, Palma, 1994, publicado con el mismo título en Palma 1996.

3 Se ha tenido en cuenta también, entre otras fuentes, la documentación privada confiscada a los judeoconversos (chuetas) en las persecuciones de finales del siglo XVII. Contienen una magnífica información debido a la especial vinculación de este grupo socio-económico con la actividad comercial y el control ejercido sobre el mercado interior a través de las botigues de telas. La primera confiscación, sin embargo, se produce a finales de los años setenta por lo que, como se verá más adelante, obstaculiza cualquier posibilidad de que dicha documentación contenga datos del fenómeno que se quiere entender en toda su dimensión.

4 Las diferencias surgidas entre las series obtenidas a través del derecho de contrabando y las derivadas del Victigal de Mar se deben a que la primera fuente analiza el año natural y la segunda el año económico. Además, el derecho de contrabando sólo contabiliza una parte, aunque fundamental, del mercado. BiBILon AmENGunt, A., «El derecho de contrabando en las relaciones comerciales mallorquinas (1640-1720)», en C. Martinez Shaw (ed.), El Derecbo y el Mar en la España Moderna, Granada 1995, pp. 31-38.

5 La fuentes disponiblesno ayudan a anticipar el análisis a fechas anteriores a 1630. Por otra parte, existen estudios que dan explicación, a través de fuentes idénticas, a la evolución de los intercambios durante la segunda mitad del siglo XVIII. MANERA Eri3ina, Carles, Comerg i capital mercantil a Mallorca, 1720-1800, Palma 1988.

6 JUnN VIDAl., Josep, «La evolución de la producción agrícola en Mallorca durante la Edad Moderna»: Moneda y Crédito 145 (1980) y "Crisis de subsistències i aprovisionament blader de Mallorca durant l'Edat Modernac: Randa 26 (1990). 
surgidas a raiz de la pragtmática de 1648 conducirá a una contrarreforma en la década de los ochenta por la cual no se acaban de resolver los problemas del bien común ${ }^{7}$. En segunda instancia, en 1652 la isla recibe el impacto, esperado pero no por ello menos brutal, de la peste que cuatro años antes se inició en Argel y que ya ha dejado un apreciable número de bajas por la costa levantina española.

3. A finales de los setenta y principios de los noventa las persecuciones e incautaciones de bienes que la Inquisición tealiza sobre los chuetas (judeoconversos) convulsionarán la comunidad insular y además de las relaciones sociales se verán fuertemente alteradas las estructuras comerciales y financieras.

4. La segunda década del siglo XVIII incorpora unos rasgos significativos ligados al nuevo marco jurídico-institucional creado con la Nueva Planta de Gobierno y, desde el punto de vista que nos ocupa en este análisis, a las alteraciones que la peste provenzal provocará sobre los intercambios y la vigencia de una legislación proteccionista que afecta directamente a las importaciones textiles".

Pata levar a cabo la propuesta inicial y tratar el consumo de telas es preciso definir la estructura del comercio mallorquín durante el siglo XVII.

\section{IA ESTRUCTURA DE LOS INTERCAMBIOS}

Especialmente a partir de los años sesenta en su conjunto el comercio exterior se vertebra en torno a dos grandes apartados: las estructurales ventas de aceite y las compras coyunturales de trigo. Las exportaciones están permanentemente dominadas por el aceite que, con fuertes oscilaciones interanuales ", se mantiene entre el 37'5\% (1699-1700) y el 90'5\% (1715-1716) del valor de las ventas, aunque la media de todo el período está cercana al $64 \%{ }^{10}$.

7 Casnnova Todol, Ubaldo, La regulación contributiva del reino de Mallorca durante el sigho XVII (De la Real Pragmática de 1600 a la Contordia de 1684), Tesis doctoral inédita, Palma y «La 'Universal Consignació' a lo largo del siglo XVII: la concordia de 1684k: Estudis Baleàrics 26 (1987); Brillon AmEngunl, Andreu, «Reforma econòmica i 'legalització' del contraban a Mallorca, 1650-1720«: Randa 26 (1990).

8 Santamarua, Alvaro, Nueva Planta de Gobierno de Mallorca. Enfizeusis urbana y real cabrevación, Palma 1989, especialmente pp. 397-570 y JUNN ViDs, Josep, El sistema de gobierno en el Reino de Mallorca (siglos XV-XVII), Palma 1996.

- JuAN VIDN, Josep, «La producción de aceite en Mallorca durante la Edad Moderna y su papel en la economía mallorquinas: BSAL 832-833 (1980), DAvIU PONs, Guillem, «La producció d'oli a Mallorca, segle XVIII. Aproximació en base a la documentació fiscaly: I Col.logui d'Història Agrària, Valencia 1983, págs. 391-410.

10 La fluctuación de las cosechas se refleja en la exportación. En 1687-88 se produce la exportación record de todo el período con 3'9 millones de litros (valorados en 277.000 libras mallorquinas) mientras el año siguiente el embarque cae un $43 \%$. Aún así, la extracción demuestra una major estabilidad durante el periodo 1657-1691 cuando el aceite representa, por término medio, el $72 \%$ del valor de las exportaciones, mientras en la etapa 1697-1718 cae al $54 \%$. Los factores determinantes de esta pérdida de peso en el conjunto de las ventas se debe

Hípania, LIX/3, núm 203 (1999) 897-924 
En un segundo escalón, aunque a mucha distancia del aceite, se halla la equilibrada participación de las manufacturas de lana y los alimentos, con una representatividad media de un $16 \%$ para cada sector ${ }^{11}$. La estrecha horquilla que cierra las ventas está integrada por una larga lista de bienes de bajo valor y unas exiguas materias primas y reexportaciones orientadas al mercado balear ${ }^{12}$.

La generosidad de las fuentes al favorecer el cálculo de la estructura de las exportaciones desaparece cuando se analizan las compras ${ }^{13}$. A pesar de que no se contabiliza el trigo, los alimentos se consolidan al frente de las importaciones con una media cercana al $40 \%$ del valor total. El arroz por la cantidad (unas 225 toneladas anuales) y el azúcar y la pimienta por el valor son los productos estrella, seguidos a distancia de frutos secos y pescado ${ }^{14}$. Manufacturas textiles,

al descenso absoluto del número de litros y a las restricciones impuestas por una legislación que limita la carga cuando los precios llegan al techo de 20 sueldos/cuartán como sucede en 1699 y 1708. Junn VIDA., Josep, "La producción de aceite...»; Bibl.onI AMLNGUAl, Andreu, Mercaders i navegants a Mallorca durant el segle XVII. L'oli com indicador del comery mallorqui (1650-1720), Palma 1991, págs. 27-54 y, del mismo autor, El comerg exterior de Mallorca. Homes, mercats i productes dintercanvi (1650-1720), Palma 1995, págs. 20-81.

11 Las manufacturas textiles están integradas por la constante presencia de paĩos y mantas y una participación coyuntural de estambre y seda. Por su parte, el queso representa, por término medio, un $61 \%$ del valor de las exportaciones alimenticias aunque en cuatro ocasiones se situa por encima del $80 \%$. Al igual que ocurte con el resto de productos el papel del queso en el conjunto de las ventas está vinculado a los excedentes de aceite. De este modo, los 3'6 millones de litros de aceite cargados en 1656-1657 provocan que las 128 mil piezas de queso embarcadas ese año sólo representen el $9 \prime 1 \%$ de las exportaciones, a la vez que significan el $82 \%$ de las ventas estrictamente alimenticias. Por el contrario, cuando en 1707-1708 el aceite se reduce a 5 mil litros, 66 mil piezas de queso equivalen al $28 \%$ de la exportación total. El resto de alimentos lo integra una lista de productos de baja valoración (alcaparras) y/o cuya presencia es intermitente (almendras, algartobas, habas, bizcocho, vino). Caso aparte merece el aguardiente que se impone como primer producto de la exportación a finales de siglo coincidiendo con la crisis del aceite. BiBlLoni AMENGUAL, Andreu, El comerf exterior..., pp. 82-104.

12 Los productos más frecuentes en los embarques son: sombreros, escobas, yeso y jabón.

13 El cómputo del valor de las importaciones se ve dificultado por dos factores: por una parte, los libros de la aduana no incluyen las entradas de trigo al no estar sujetas al pago del victigal. Este problema queda minimizado por la favorable situación de la producción agricola entre 1650 y 1720 con escasas crisis de subsistencias. En segundo lugar, la multitud de bienes descargados por cada comerciante se presentan con una valoración total por individuo, por lo que resulta dificil desagregar el valor de cada producto. Este problema se ha solucionado, parcialmente, al realizar una serie de estimaciones a partir de valoraciones del mismo año que permiten identificar el $75 \%$ del valor de las importaciones. Véanse los diferentes trabajos de JUNN VIDAL, Josep, «Las crisis agrarias y la sociedad en Mallorca durante la Edad Modernas: Mayurga 16 (1976); «La evolución...» y «Crisis de subsistències...«; y de CASANOVA TODOL., Ubaldo, «El déficit alimenticio del Reino de Mallorca a lo largo del siglo XVII y sus problemas de abastecimienton: Mayurga 21 (1985-1987).

14 El mayor volumen de arroz se descarga en $1715-16$ con 17658 quintales. Su valor, estimado en unas 60 mil libras mallorquinas, significa el $46 \%$ de las compras alimenticias y el $173 \%$ del conjunto de las importaciones. En este mismo año se consiguen otros techos excepcionales: las entradas de azúcar (2100 quintales) sólo serán superadas por los 2660 quintales de 
materias primas y otros bienes manufacturados se reparten una cuota que oscila entre el $25-15 \%$.

CUADRO 1. Composición de las principales exportaciones de Mallorca. 1657-1718

\begin{tabular}{|c|c|c|c|c|c|c|c|c|}
\hline \multirow{3}{*}{ Años } & \multicolumn{5}{|c|}{ Manufacturas textiles } & \multicolumn{2}{|c|}{ Otros } & \multirow{3}{*}{$\begin{array}{c}\text { Subtotal } \\
\%\end{array}$} \\
\hline & \multirow{2}{*}{$\begin{array}{c}\text { Paños } \\
\%\end{array}$} & \multirow{2}{*}{ Mantas } & \multirow{2}{*}{$\frac{\text { Estambre/seda }}{\%}$} & \multicolumn{2}{|c|}{ Total textil } & \multirow{2}{*}{ Aceite } & \multirow{2}{*}{$\begin{array}{c}\text { Queso } \\
\%\end{array}$} & \\
\hline & & & & $\begin{array}{l}\text { libras } \\
\text { mallorq. }\end{array}$ & $\%$ & & & \\
\hline $1656-57$ & 1,7 & 1,5 & 0,1 & $14.5 \% 1$ & 3,3 & 82,4 & 9,1 & 94,8 \\
\hline $1660-61$ & 3,1 & 2,5 & 0,2 & 16.520 & 5,8 & 81,8 & 7,3 & 94,9 \\
\hline $1672-73$ & 6,2 & 3,9 & 0,8 & 26.205 & 10,9 & 76,6 & 7,1 & 94,6 \\
\hline $1676-77$ & 7,6 & 7,8 & 2,7 & 28.810 & 18,1 & 61,2 & 11,7 & 91,0 \\
\hline $1678-79$ & 6,6 & 3,7 & 2,0 & 22476 & 12,3 & 68,2 & 8,8 & 89,3 \\
\hline $1680-81$ & 10,6 & 3,1 & 2,4 & 31.827 & 16,1 & 70,0 & 8,7 & 94,8 \\
\hline $1683-84$ & 4,0 & 2,2 & 4,5 & 24.073 & 10,7 & 78,6 & 6,5 & 95,8 \\
\hline $1684-85$ & 9,9 & 3,9 & 10,4 & 31.096 & 24,2 & 57,0 & 8,4 & 89,6 \\
\hline $1687-88$ & 3,9 & 1,4 & 3,6 & 29.122 & 8,9 & 85,0 & 3,3 & 97,2 \\
\hline $1688-89$ & 10,1 & 3,0 & 3,8 & 39.196 & 16,9 & 74,2 & 4,3 & 95,4 \\
\hline $1689-90$ & 17,0 & 4,7 & 5,7 & 48.368 & 27,4 & 55,6 & 11,0 & 94,0 \\
\hline $1690-01$ & 11,7 & 2,5 & 7,3 & 46.626 & 21,5 & 72,0 & 2,1 & 95,6 \\
\hline $1697-98$ & 1,9 & 1,7 & 1,9 & 7.778 & 5,5 & 83,6 & 3,6 & 92,7 \\
\hline $16 \% 8-99$ & 5,0 & 6,0 & 2,6 & 9.451 & 13,6 & 0,3 & 7,6 & 21,5 \\
\hline $1699-00$ & 14,7 & 11,6 & 1,4 & 13.131 & 27,7 & 37,5 & 12,7 & 77,9 \\
\hline $1700-01$ & 13,8 & 8,6 & 3,1 & 15.075 & 25,5 & 55,3 & 11,2 & 92,0 \\
\hline $1701-02$ & 2,8 & 3,2 & 0,9 & 13.135 & 6,9 & 82,9 & 5,0 & 94,8 \\
\hline $1702-03$ & 7,4 & 3,7 & 0,8 & 16.048 & 11,9 & 69,9 & 8,5 & 90,3 \\
\hline $1703-04$ & 14,6 & 6,2 & 0,8 & 19.430 & 21,6 & 51,4 & 19,1 & 22,1 \\
\hline $1707-08$ & 18,6 & 12,1 & 0,6 & 9.874 & 31,3 & 0,0 & 27,9 & 59,2 \\
\hline $1715-16$ & 1,3 & 1,2 & 0,1 & 4.510 & 1,6 & 90,5 & 0,6 & 22,7 \\
\hline $1717-18$ & 2,4 & 8,2 & 0,0 & 6.658 & 10,6 & 70,8 & 2,4 & 83,8 \\
\hline Mcdia & 7,9 & 4,6 & 2,5 & & 15,1 & 63,8 & 8,5 & 87,4 \\
\hline
\end{tabular}

Fuente: ver nota n. $^{\circ} 2$.

Este análisis no deja de ser una visión estática de los intercambios mallorquines correspondientes a nueve décadas a partir de una simple media aritmética. Sin embargo, el marco temporal aludido aparece como un período compartimentado y dinámico en el que se impone un cambio estructural que rompe con los esquemas vigentes desde la baja edad media y traza algunos de los rasgos característicos del siglo XVIII. Los estudios existentes sobre la Ma-

1702-03; la pimienta, con 292 quintales, está por detrás del registro de 1698-99 en el que se consignan un total de 415 quintales. ARM, AH, 1381, 1377, 1544.

Hispuntu, LIX/3, núm. 203 (1999) 897-924 
llorca del seiscientos plantean que su desarrollo económico encuentra en la década de los sesenta el límite de la crisis e inicia una recuperación que derivará en el crecimiento del setecientos. El tramo final del siglo XVII aparece, por lo tanto, como una fase de transición prolongada hasta, al menos, 1720 que se define por una serie de factores que afectan tanto a la producción como al consumo ${ }^{15}$.

Por una parte, entre 1680 y 1720 la producción agrícola alcanza un incremento sin par en el resto de la edad moderna. El fenómeno afecta a la práctica totalidad de subsectores. El crecimiento de las cosechas de trigo, cebada, avena y legumbres se da paralelamente a la extensión del cultivo de la vid y el consiguiente aumento de la participación del vino y el aguardiente en el comercio. Los efectos de esta dinámica se hacen sentir en la necesaria contracción del sector pecuario con el descenso de la cabaña ovina y una fuerte disminución de las piezas de queso exportadas. Al mismo tiempo, el aceite se sostiene como eje vertebrador de la economía insular permaneciendo al frente de las exportaciones a pesar de que la producción total descienda a principios de la década de los noventa ${ }^{16}$. A la mayor disponibilidad de alimentos básicos hay que sumar los efectos de la diversificación del consumo a partir: de la multiplicación de las entradas de arroz valenciano, frutos secos catalanes, pescado y coloniales como el azúcar, la pimienta o el cacao.

En segundo lugar, la totalidad de las manufacturas se ven afectadas por un cambio radical. Los sectores del cuero y el metal alcanzan un dinamismo sin precedentes pero su impacto se sitúa por detrás del que afecta al textil. A medida que se acerca el final del seiscientos decrece el papel, en otro momento vital, de las telas de lana y seda en el conjunto de las exportaciones ${ }^{17}$. El análisis de las importaciones incorpora la doble perspectiva de las materias primas y las telas. Respecto a las primeras se constata la tímida pero creciente penetración de fibra de algodón al tiempo que el lino se consolida al frente de la demanda local. Este comportamiento se traduce en una tendencia clara pero de difícil

15 JUAN VIDAL, Josep, «La evolución...»; MANLra Erbins, Carles, «Resistir i créixer. Canvi econòmic i classes socials a la Mallorca del segle XVIII): Randa 26 (1990); BIBILONI AMENGUN., Andreu, El comerf exterior..., pp. 19-104.

16 BibiLONi AMLNGUnL, Andreu, Mercaders $i$ navegants..., pp. $27-47$.

17 Seviliano Colom, Francesc, «Artesanía textil de la lana mallorquina (siglos XIV y XV)n: Produzione, commercio e consumo dei panni di lana (s. XII-XVII), Florencia 1976, pp. 537-552; MACARE, Pierre, Majorque et le commere international (1400-1450 environ), Lille 1986; DEYA BAUZA, Miguel josé, «Tradición e innovación en el sector textil mallorquín a fines del siglo XVII»: $M a$ yurga 22 (1988); GIUIFRIDA, A., «Aspetti del commercio internazionale dei panni in Sicilia nella prima meta del sec. XVI): Produžione, commercio e consumo dei panni di lana (nei secoli XII-XVIII), Florencia 1976; BRESC, Henri, «La draperie catalane au miroir sicilien, 1300-1460m: Acta Historica et Arthaeologica Medievalia 4 (1983); VNQUER BENNASSAR, Onofre, «Les manufactures mallorquines de teixits $\mathrm{i}$ de pells a la segona meitat del segle XV: importacions i exportacions»: BARCELO Clkesn', Maria (ed.), La manufactura urbana i els menestrals (ss. XIII-XVI), IX Jornades d'Estudis Històtics Locals, Palma 1991; Bernatr Roca, Margarida, Els III Mesters de la Llana a Ciutat de Mallorca (ss. XIV-XVII), Palma 1995. 
evaluación por la que los productores insulares pueden estar afrontando un cambio productivo por el que se sustituyen las fibras de otigen animal por las de procedencia vegetal. El estado actual de los estudios sobre el sector textil mallorquín del siglo XVII no permiten profundizar demasiado sobre la hipótesis que se acaba de plantear ${ }^{18}$. Sin embargo, los datos procedentes del comercio exterior apoyan con contundencia esta perspectiva. A lo largo del siglo XVII la evolución del consumo textil refleja un doble efecto: el incremento absoluto del número de piezas importadas y una importante diversificación que reiteta el triunfo de las telas de lino y algodón y/o mezcladas como prueba del acercamiento a las pautas vigentes en el resto de Europa ${ }^{19}$.

El impacto de la demanda sobre estos dos cambios que determinan el consumo sigue sin conocerse bien. Por una parte, G. Jover entiende que a finales del siglo XVII se produce una mejora en la capacidad de consumo de las clases populares, por lo que no puede despreciarse que una parte de su renta se desviara hacia el consumo de telas de lino y algodón ${ }^{20}$. Por otra parte, sin olvidar el carácter elástico de esta demanda, los datos globales de población para toda Ia isla todavía deben apoyarse en los valores de 1667 sin existir otra referencia fiable para la segunda mitad del seiscientos ${ }^{21}$. Con estos mimbres resulta para-

18 La historiografia insular más reciente ha sido prolífica con estudios sobre el sector lanero del siglo XVII (Bernsir RocA, Margarida, Els III Mesters... y Dlya BauzA, Miquel J., La manufactura de la lana en la Mallorca del siglo XV, Palma 1997 y La manufactura de la llana a Mallora (segles XVT i XVTI), Palma 1998. El lino y el algodón, sin embargo, siguen huérfanos.

is Véanse al respecto los trabajos de CirapMAN, S.D. y CiIASSAGNE, S., European Textile Printers in the Eighteen Century: a Study of Peel and Oberkampf, Londres 1981; Tiomson, James, La indústria d'indianes a la Barcelona del segle XVIII, Barcelona 1990, Els origens de la industrialització a Catalunya. El cotó a Barcelona (1728-1832), Barcelona 1994 y «Intervención del Estado en la industria catalana de estampado de telas en el siglo XVIII», en BᄃRG, Maxine (ed.), Mercados y manufacturas en Europa, Barcelona 1995, pp. 74-110; SÁNCIIEZ SUÁr:Z, Alejandro, «La era de la manufactura algodonera en Barcelona, 1736-1839\%, Estudios de Historia Social, 48-49 (1989), pp. 65-113 y «La indianería catalana: ¿mito o realidad?, Revista de Historia Industrial, 1 (1992), pp. 213-232; MARTín CorkAs.zs, Eloy, "Consumo de algodón en la Cataluña de la segunda mitad del siglo XVII y nacimiento de la indianerían, VI Simposio de Historia Económica, Bellaterra-Barcelona 1992 y «La importación de telas de algodón levantino y los inicios del estampado en Cataluña», Revista de Historia Industrial, 6 (1994), pp. 47-74; FONTANA LizAro, Josep, «Sobre el comercio exterior de Barcelona en la segunda mitad del siglo XVII. Notas para una interpretación de la coyuntura catalanas: Estudios de Historia Moderna 5 (1955), pp. 199-218; FuKASAWA, Katsumi, Toilerie et commerce du Levant, d'Alep à Marseille, París 1987, págs. 15-45.

20 Jover, Gabriel: Desenvolupament economic i societat rural a Mallorca. Feudalisme, latifundi i pagesta, 1500-1800, Tesis doctoral inédita, Univ. de Girona, 1997, págs. 569-580 y 640-687, sosciene que la mejora en las condiciones de vida de las rentas más bajas se evidencia por el descenso del precio de productos básicos como el trigo y el aceite, un crecimiento lento de los salarios reales agrícolas y de determinados artesanos, el aumento de la producción, el descenso de la carga feudal en determinadas zonas y un lento crecimiento de la población.

21 Domíngulz Oritz, Antonio, La sociedad española del siglo XVTI, Madrid 1963-1970, establece el conjunto de la isla en 99192 habitantes para 1667. Sunu PUIG, Jaume, uDemografia rural mallorquina del segle XVIII»: Mayurga 16 (1976) habla de 81663 almas para 1648 mientras

Hi.̧æaniu, I.IX/3, núm. 203 (1999) 897-924 
dójico evaluar el impacto que sobre la sociedad insular tienen las migraciones de mallorquines hacia la costa peninsular con el fin de ocupar el espacio abandonado por los moriscos ${ }^{22} \mathrm{y}$, a la vez, calibrar las consecuencias de la peste de $1652^{23} \mathrm{o}$ de la Guerra de Sucesión. Datos imprescindibles para responder a por qué a pesar del notable incremento de las cosechas y a la diversificación de los alimentos importados entre 1690 y 1715 la isla persiste en sus necesidades de seguir importando trigo. Paralelamente a un incremento demográfico tenue la principal explicación debe buscarse en factores exógenos como el aumento de la demanda urbana provocada por la posible migración y, sobre todo, el incremento de la demanda pública derivada de los compromisos de la corona o la ciudad con sus aliados ${ }^{24}$.

De los dos factores que sostienen el cambio estructural que afecta a la economía mallorquina cabe insistir en el desarrollo de las manufacturas estableciendo una clara frontera entre el subsector textil y el resto de actividades artesanales.

\section{LA MANUFACTURA TEXTIL}

A través de los datos contenidos en los cuadros 1 y 2 se aprecia la magnitud de los cambios que afectan al sector de forma que tanto importacio-

otros, a la capital, le adjudican 27585 personas en 1642,34000 en 1650,32000 en 1652 y 39000 en 1700 (AAVV, Histònia de Malloria, Palma 1980).

22 Cosrn MAs, J.: «La repoblació mallorquina a la Marina Alta i al seu entorn en el segle XVII), Trabajos de Geografia 34 (1977-1978), pp. 87-91.

2.3 Durante las guerras de Sucesión y de Independencia Mallorca actuara de refugio al absorber una corriente migratoria procedente de las costas peninsulares (RourA, Lluis, L'Antic Règim a Mallorca. Abast de la conmoció dels anys 1808-1814), Palma 1985. No se puede descartar que a mediados del siglo XVII la isla hubiera asumido una función similar. Este supuesto toma forma con la extensión cronológica y espacial del contagio según la cual a partir de 1647 Valencia lo proyecta en dirección sur y norte. Ese mismo año Alicante está infectada llegando a Cádiz y Sevilla dos años después. Barcelona recibe al azote de la peste bubónica en 1650 y al cabo de dos años la exporta a Mallotca (NADAL OiLfir, Jordi, La población española (siglos XVI a XX), Batcelona 1984, págs. 38-43). La isla permanece cinco años con patente limpia tespecto a Valencia y dos a Barcelona. ¿Qué sucedió durante ese tiempo?. Datos parciales prueban el tránsito de algún comerciante extranjeto que en 1650 llega a la isla procedente de Barcelona huyendo del contagio. El camino está abierto pero su magnitud se desconoce.

24 El avituallamiento de la milicia acuartelada en la isla condiciona la disponibilidad alimenticia de sus habitantes, pero el grueso de la demanda procede del exterior. Cataluña capitaliza esta corriente durante la Revolta y de la Guerra de Sucesión con la ayuda triguera que recibe de diferentes centros del reino (Cremadis GriñN; Román ClanvnNies, Cándido, mAbastecimiento de granos al Principado de Cataluña durante el asedio de Barcelona y la Guerra de Sucesión (1697-1712)»; Primer Congrés d'Històna Moderna de Catalunya, Barcelona 1984, pp. 569-579 Mallorca se suma a las obligaciones de la corona de abastecer las flotas aliadas rebajando o eliminando aranceles para beneficio de genoveses, holandeses e ingleses. Representantes de estas naciones en la isla aprovechan su oportunidad e inician un activo contrabando. La aparición del Derecho de la Secretaria del Virrey durante el siglo XVII se produce como instrumento regulador de las actividades comerciales desarrolladas entre aliados (Birmoni Amingunal, Andreu, Mercaders i navegants..., p. 99). 
nes como exportaciones encuentran una clara frontera en la década de los años ochenta.

\section{a. La exportación textil}

Las aisladas cifras de 1635 prueban la permanencia de los esquemas vigentes durante buena parte del siglo XVI por los cuales la exportación insular se sostiene sobre los paños de baja calidad identificados con las estameñas y los escots ${ }^{25}$. Sin embargo, a lo largo del seiscientos la oferta se diversifica con el concurso de las frisetas, iniciándose una tendencia por la cual en un primer momento se equipara el volumen de exportación para llegar al predominio de las terceras sobre las dos anteriores ${ }^{26}$. Después de una etapa especialmente positiva a finales de los años ochenta, entre 1690 y 1720 se produce un descenso absoluto de la extracción de las tipologías mencionadas y el hundimiento conjunto de la exportación de paños. En el caso de las mantas la trayectoria es similar pero se introduce una nueva cronología. La exportación se mantiene al alza hasta finales de los años setenta cuando se inicia un proceso de estancamiento con intensas fluctuaciones en las dos últimas décadas del XVII, pero al contratio de lo que sucede con los paños, durante el siglo XVIII la exportación se recupera rozándose los máximos alcanzados en 1630 y las mantas se consolidan como uno de los principales productos mallorquines que puede competir en el mercado exterior ${ }^{27}$.

La contribución de la manufactura lanera se cierta con la comercialización de excedentes de estambre mezclado con seda que acotan todavía más la cronología que define la decadencia de las tradicionales manufacturas insulares. La elevada repercusión de este producto se debe a los ritmos de exportación de la década de los ochenta cuando, por término medio, el valor de las ventas al exterior superan las 10.000 libras. En 1685 el estambre y seda logra un máximo relativo al significar el 10 ' $4 \%$ del valor de las exportaciones y más del $40 \%$ de

25 DeYa Bay $\angle A$ insiste en la pérdida de calidad de los paños insulares a lo largo de la Baja Edad Media que, intensificada en los siglos siguientes, enfrentará a los diferentes grupos implicados en su producción-distribución, «La implantación de la 'Bolla del Redreç': un aspecto del enfrentamien to entre mercaderes y artesanos en la Mallorca del siglo XV': Homenatje a Antoni Mut Calafell, arxiver, Palma 1993, pp. 63-78.

26 El papel de las frisetas en el conjunto de la economía insular y, especialmente, en el seno del sector textil merece un futuro estudio más detallado. A pesar de que las fuentes aduaneras no certifican el tipo de tela que se embarca, las estimaciones realizadas permiten apuntar que la variedad de friseta que se exporta con mayor frecuencia es la veintena, caracterizada por tener una longitud y precio similares a la estameña pero de doble anchura ( 1 cana $=1$ '564 metros). De esta forma, cabe la posibilidad de gue, sin despreciar otros aspectos cualitativos como la calidad, el grosor o los tintes utilizados, en las series que se expresan en número de piezas se aplique un coeficiente ponderador que duplique el papel de la friseta.

27 Manera Erbins, Carles, "Manufactuta textil y comercio en Nallorca, 1700-1830", Revista de Historia Económica, 3 (1988), pp. 528-529 y, especialmente, p. 532 (Cuadro 2).

Ii.quanta, LIX/3, núm. 203 (199\%) 897-924 
los excedentes textiles, mientras en 1691 se alcanza un máximo absoluto al exportarse más de 29.000 metros valorados por encima de las 18.500 libras mallorquinas. Hacia finales de la década de 1690 la crisis es un hecho corroborada por el acelerado descenso de la exportación y por la reacción de los productores insulares que, de nuevo, exigirán medidas proteccionistas ${ }^{28}$.

CUADRO 2. El comercio textil en el puerto de Ciutat de Mallorca. 1636-1718

\begin{tabular}{|c|c|c|c|c|c|}
\hline \multirow{3}{*}{ Años } & \multicolumn{3}{|c|}{ Exportaciones } & \multicolumn{2}{|c|}{ Importaciones } \\
\hline & Paños & Mantas & Estambre y seda & Telas & indianes/telas \\
\hline & en piezas & en unidades & en canas & en plezas & en $\%$ \\
\hline $1635-36$ & 5.029 & 5.283 & 464 & 2.156 & 0,0 \\
\hline $1356-57$ & 837 & 1.905 & 723 & 4.462 & 0,0 \\
\hline $1660-61$ & 878 & 2.248 & 717 & 8.638 & 0,0 \\
\hline 1672.73 & 1.341 & 3.168 & 1.248 & 11.360 & 0,0 \\
\hline 1676.77 & 1.115 & 4.219 & 2.920 & 10.131 & 19,5 \\
\hline 1678.79 & 1.049 & 2.233 & 1.661 & 11.142 & 0,5 \\
\hline $1680-81$ & 1.835 & 2.214 & 2.041 & 10,088 & 23,5 \\
\hline $1683-84$ & 906 & 1.630 & 9.905 & 5.259 & 13,0 \\
\hline $1684-85$ & 1.303 & 1.701 & 13.452 & 4.156 & 1,8 \\
\hline $1687-88$ & 1.226 & 1.567 & 13.027 & 8.415 & 6,6 \\
\hline $168(8-8)$ & 2.323 & 2.418 & 10.035 & 10.689 & 7,3 \\
\hline $1689-90$ & 3.158 & 2721 & 11.883 & 4.672 & 2,8 \\
\hline $1690-91$ & 2.585 & 1.836 & 18.556 & 6.543 & 5,7 \\
\hline $1697-98$ & 267 & 681 & 3.160 & 7.964 & 13,3 \\
\hline $1698-99$ & 257 & 1.120 & 2.150 & 18.441 & 13,9 \\
\hline $1699-00$ & 654 & 1.532 & 778 & 8.440 & 22,2 \\
\hline $1700-01$ & 790 & 1.538 & 2.138 & 7.905 & 10,6 \\
\hline $1701-02$ & 581 & 1.919 & 2.164 & 11.579 & 17,8 \\
\hline $1702-03$ & 1.249 & 1.662 & 1.272 & 13.027 & 21,8 \\
\hline $1703-04$ & 1.325 & 1.880 & 849 & 6.127 & 16,0 \\
\hline $1707-08$ & 569 & 1.302 & 257 & 11.260 & 25,2 \\
\hline $1715-16$ & 186 & 601 & 292 & 14.169 & 28,7 \\
\hline $1717-18$ & 141 & 1.586 & 0 & 11.885 & 0,0 \\
\hline
\end{tabular}

Fuente: ARM, Libros de la Aduana. 1 cana $=1$ '564 metros.

28 A pesar de que el colegio de torcedores de seda no se constituye hasta 1685 la ocupación se conoce desde el último cuarto del siglo XVI a través de la difusión dada por ei valenciano Miquel Magraner (QuLtGlAs, Bartolomé, Los gremios de Mallorca, siglos XII al XIX, Palma 1980, pp. 231-232). La crisis se prevee en plena fase expansiva. En 1686 los torcedores de seda inician un litigio que se prolongará más de quince años con los vendedores al por menor (marxandos) y en 1688 el Gran $i$ Genera/ Consell secibe la comunicación de los perjuicios que implica la entrada de telas de seda [ARM, AH, AGC, 71 (1688)]. 
Durante el siglo XVII son constantes las denuncias de los productores vinculados a la lana sobre los motivos que explican la decadencia del sector ${ }^{20}$. El factor aludido con mayor frecuencia es la pérdida de calidad de los paños que se exportan, favorecida por la creciente tendencia a la defraudación de unos artesanos que se aprovechan de una legislación cada vez más tolerante ${ }^{30}$. Los tejedores de lana se quejan, así, de los perjuicios que provoca la sustitución de la bolla (sello) de cera por la de plomo, más fácil de falsificar. La solución propuesta se dirige a intensificar el control de calidad sustituyendo la aplicación del sello al final del proceso productivo por la sucesión de exámenes al final de cada una de las etapas. De esta forma, cada gremio asu-

29 Brannir Rocn explica la crisis de la lana de finales del siglo XVII a partir de tres factores: la pérdida de calidad de los paños arrastrada desde el siglo XV; la exportación de lana en bruto o semielaborada; y la reducción de la cabaña ovina (Telers $i$ teixidors a Mallorca. Apunts

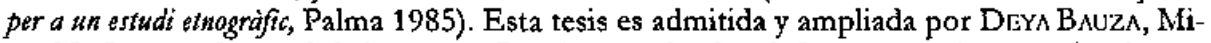
quel J., La manufactura de la lana..., pp. 73-123 cuando aborda las repercusiones reales de una intensa legislación que afecta a un sector lanero en expansión sobre las disputas entre el capital mercantil y los gremios afectados por la reforma de finales del siglo XV. Exige la necesidad de una lectura socio-económica por la que el enfrentamiento no se reduce al dualismo mercaderes-menestrales y se amplia al comportamiento y a los intereses derivados del carácter heterogéneo de la estructura de la menestralía. Así, los artesanos, y especialmente los pelaires, no constituyen un frente común al capital comercial ya que algunos de ellos, los más poderosos, se identifican y defienden una política económica parecida a la de los mercaderes exportadores. Esta óptica, que implica un control del proceso productiva y la exportación, parece adecuada para entender la capacidad económica manifestada por los pelaires en las dos centurias siguientes tanto en el mercado interior como en el exterior. Un análisis a largo plazo del sector lanero se halla en DEYA BAuzA, Miquel \}., La manufactura de la lana en Mallorca, 1400-1700: gremios, antesanos y comerciantes, tesis doctoral inédita, Universitat de les Illes Balears, 1996.

30 En un informe de 1652 el síndico del colegio de los tejedores de lana denuncia que la $\mathrm{M}$ con que en Sicilia se matca a los paños mallorquines desde principios de siglo ha dejado de ser signo de prestigio para convertirse en sambenito de ropa falsa. Al tratarse de parte interesada el síndico, Joaquim Antoni Carbonell, no duda en culpar del fraude al podetoso gremio de pelaires que se aprovecla de la debilidad de los agremiados tejedores para imponer condiciones sobre el tejido. La acusación apunta que por cada pieza de estamenya se estaría reduciendo la trama en alrededor de un 30\%. El síndico exculpa a los tejedores debido a la supuesta posición de dependencia respecto a los pelaires ya que ivahent los dits texidors, que si no fan el gust de dits parayres li llevaran la feyna, y tant matteix attrobaran altri qui la fassa, encare que honrat (...) fa lo que no devia fer en tant gran dany de tot aquest Regne, y de si mateix) ("viendo dichos tejedores que si no realizan el encargo de los pelaires les quitarán el trabajo y, de todas formas, encontrarán otros que lo hagan, aunque honrado (...) hace lo que no debía hacer siendo un gran daño para todo este Reino y para si mismon traducción del autor) [ARM, Audiència, Gremis, Caixa 8, Expedient 9, ff. 16v-17]. El carácter estructural del problema queda explicado en los trabajos de Deyn Bauza, Mquel J., «La industría rural textil en la Mallorca moderna: producción y formas de comercialización interion: Estudis d'Història Econòmica 2 (1988), pp 15-41 y aLa comercialización de lana en la Mallorca del siglo XV: entre el proteccionismo y el frauden: BARCII O CRFspi, Maria (ed), La manufactura urbana i els menestrals (ss. XIII-XVI), IX Jornades d'Estudis Històrics Locals, Palma 1991.

Ilippania, 1.IX/3, núm. 203 (1999) 897-924 
miría las funciones que le son propias y determinaría la superación o no de la calidad exigible ${ }^{31}$.

\section{b. La importaciôn textil}

Paralelamente a este proceso de estancamiento y decadencia el mercado mallorquín se ve inundado por una creciente avalancha de telas que aumentan tanto en el número de las variedades como en el volumen de las compras ${ }^{32}$. Su repercusión sobre la economía insular es especialmente significativa a partir de la década de 1680 y agudiza el déficit comercial con la sustitución de mercados y la alteración de las pautas de consumo. Los productores locales pudieron intentar responder a esta situación adaptándose a la fabricación de telas similares a las importadas a través de una creciente demanda de fibra de lino y algodón, pero se verían arrastrados a una guerra perdida a raíz de su baja competitividad. Durante este proceso los artesanos mallorquines requieren una cantidad creciente de productos tintóreos que se podría desviar, en parte, a la fabricación de las nuevas telas. A estas alturas existen serias dudas de que la demanda interna fuera suficiente para impulsat una industria tendente a sustituir las importaciones, como sucedió en Cataluña ${ }^{33}$. Parece más claro, sin embargo, que aún habiendo existido ésta no se consolidó.

Para analizar los ritmos de importación textil se ha optado por simplificar la información, recogida en el Cuadro 3, realizando cinco cortes cronológicos entre los que se ha intercalado una sexta serie correspondiente a 1687-1688 al considerarse un año crucial. Del mismo modo, al tratarse de una serie larga y de manipulación farragosa (136 tipos de telas) se ha sustituido el listado cronológico de las variedades textiles por una síntesis que resume las fibras utilizadas ${ }^{34}$. A pesar de que una parte importante de las telas no se ha identificado con fibra alguna, del cuadro 3 se deducen las siguientes observaciones:

31 Se propone que cada colegio imponga un sello acreditando el control de calidad: los tejedores respecto a la texrura, el número de hilos $y$ la longitud de las piezas, los pelaires respecto a la mezcla de las lanas y limpieza de la ropa y los bolladors de redref sobre los tintes. ARM, Gremis, Caixa 8, Expedient 9, f. 19v.

32 La contracción de las exportaciones textiles mallorquinas y el aumento de la importación de telas extranjeras coincide con el cambio que el comercio de Barcelona conoce entre 1664-65 y 1695-96. FonTAN L LAZARO, Josep, «Sobre el comercio...», p. 207.

33 Dejgndo RIbas, Josep Maria, «Pautas diferenciales en la demanda de textiles en España e Hispanoamérica durante el siglo XVIII. Sobre la demanda interna de tejidos de algodón (1728-1778)m: p. 9.

34 La relación completa de las 23 variedades textiles más importantes en el conjunto de las importaciones mallorquinas del periodo 1636-1718 se encuentra en BibiLONI AMILNGUN., Andreu, «Tráfico y consumo textil en la Mallorca del siglo XVIL): Bolleti de la Societat Arqueologica Lulliana 51 (1995), p. 164. La sistematización de variedades textiles por fibras se apoya en los datos ofrecidos por Fukasawn, Katsumi, Toilerie... y Savary dTS Brusions, Jacques, Dictoinaire universel de commerce, París 1728.

ILipania, ]JX/3, núm. 203 (1999) B97-924 
1. A medida que avanza el siglo XVII el aumento constante de la importación textil afecta tanto al número de piezas como a las variedades de telas ${ }^{35}$.

2. A finales de la década de los setenta se produce un salto cuantitativo y cualitativo que se consolidará en el decenio posterior y perdurará hasta 1716. Para mediados del seiscientos se consigue duplicar el ritmo importador y los datos de 1677 confirman que los consumidores disponen del triple de variedades que cuarenta años atrás, mientras el número de telas importadas también se multiplica por tres (o seis si se tiene en cuenta la ropa desembarcada vía corsaria). Si se sigue con 1636 como año de referencia, a finales de los ochenta las entradas se han cuadruplicado y la oferta se estabiliza por encima de las setenta tipologías textiles. El sensible retroceso de un $6 \%$ de finales de los años noventa no hace sino confirmar la cronología antes planteada que, con algunas fluctuaciones, permite que durante las dos primeras décadas del siglo XVIII se supere la media anual de 10.000 piezas de telas ${ }^{36}$.

CUADRO 3. Importación textil de Mallorca: 1636-1716

\begin{tabular}{|c|c|c|c|c|c|c|c|c|c|c|c|c|c|}
\hline \multirow{2}{*}{$\begin{array}{c}\text { Años } \\
\text { Fibra(*) }\end{array}$} & \multirow[b]{2}{*}{$\mathbf{V T}$} & \multicolumn{2}{|c|}{$1635-1636$} & \multicolumn{2}{|c|}{$1656-1657$} & \multicolumn{2}{|c|}{$1676-1677$} & \multicolumn{2}{|c|}{$1687-1688$} & \multicolumn{2}{|c|}{$1697-1698$} & \multicolumn{2}{|c|}{$1715-1716$} \\
\hline & & $\mathbf{V r}$ & $\mathbf{P}$ & $\mathbf{V T}$ & $\mathbf{P}$ & $\mathbf{v} \mathbf{T}$ & $\mathbf{P}$ & VT & $\mathbf{P}$ & $\mathbf{V T}$ & $\mathbf{P}$ & VT & $\mathbf{P}$ \\
\hline algodón & 16 & 1 & 8 & 1 & 193 & 5 & 3.483 & 11 & 4.158 & 8 & 4.525 & 11 & 7.066 \\
\hline lino & 13 & 1 & 23 & 1 & 122 & 4 & 835 & 11 & 929 & 9 & 956 & 8 & 1.588 \\
\hline lana & 19 & 6 & 81 & 8 & 121 & 7 & 175 & 9 & 341 & 12 & 212 & 11 & 335 \\
\hline seda & 10 & 2 & 177 & 4 & 37 & 6 & 59 & 5 & 263 & 3 & 71 & 1 & 5 \\
\hline pelo & 4 & 1 & 1 & 2 & 27 & 4 & 827 & 3 & 577 & 4 & 434 & 2 & 174 \\
\hline algodón/seda & 6 & 1 & 150 & 1 & 5 & 0 & 0 & 2 & 10 & 2 & 19 & 2 & 16 \\
\hline algadón/pelo & 2 & 0 & 18 & 0 & 0 & 0 & 0 & 0 & 0 & 1 & 5 & 1 & 1 \\
\hline lana/scda & 2 & 1 & 0 & 1 & 61 & 2 & 53 & 1 & 33 & 1 & 191 & 2 & 206 \\
\hline sin identificar & 64 & 8 & 1.698 & 17 & 3.896 & 28 & 4.702 & 29 & $2.104 \square$ & 18. & 1.551 & 34 & 4.778 \\
\hline Total & 136 & 21 & 2.156 & 35 & 4.462 & 56 & 10.131 & 71 & 8.415 & 58 & 7.964 & 72 & 14.169 \\
\hline
\end{tabular}

Fuente: Elaboración personal con datos de ARM, AH, 786, 1370, 1518, 1366,1544. VT= número de variedades textiles; $\mathrm{P}=$ númeo de piezas (*) algodón: bocassins, calancar, cotó blau, cotonets, cotonines, amants, angemies, anquilles, demits, escamits, indianes, fli i cotó, mussolina, toba de cotó, ruans, sengales; lino: batanones, batistes, bretanyes, cambraines, cambrais, estopetes, fotes, holandes, holandilles, llenç, librets, platilles, tananes; lana: baieta, barrega, butata, burell, cadis, cordellat, drap, droguet, escarlata, escarlatina, escot, estamenya, friseta, sempiterna, perpetuà, saial, sarja, sarseta, tela de llana; seda: armesino, espolino, gorguerant, herbatges, ormessi, tabi, tafetà, tela i toba de seda, tela estofa; pelo: ximellot, pel de camell, pelfa, picota; algodón/seda: llista, catalufa, cotó i seda, domassello, domasquillo, domàs; lana/seda: damasc, estam i seda; algodón/pelo: bombasín, fustán.

35 La única excepción en los años ofrecidos corresponde a 1676-1677 en que la serie se dispara por encima de las diez mil piezas para decaer a las ocho mil en el año siguiente. Esta tendencia debe corregirse ya que la distorsión procede de una remesa de origen corsario que provocará que en este año el número de telas fruto de presa se equipare con las del comercio regular ( 5099 por 5035). En este año el corso aporta las siguientes variedades y número de piezas: 842 bocaials o mocaials, 527 brodats (bordados), 657 escamitas, 1 demits (demitas), 299 fils blaus, 1883 indianas, 228 librets, 10 herbatges, 141 tananas, 13 telas de matalàs, 50 telas y 448 camelotes.

36 El máximo se consigue en 1698-1699 al desembarcarse más de 18.000 piezas de telas. ARM, AH, 1381.

Hipanta, LIX/3, núm 203 (1999) 897-924 
3. La importación se centra en telas de algodón y lino que, a partir del último cuarto del siglo XVII desplazan claramente a la lana y la seda. A pesar de que tan sólo se ha identificado la fibra del $53 \%$ de las variedades textiles (64 sobre 136) hay que apreciar que es a partir de finales de los años setenta cuando la información es más clara, de forma que para los tres segmentos finales del Cuadro 3 se conoce la composición del $67-80 \%$ del número de piezas.

De este modo y a pesar de que puede producirse una reestructuración que afectaría a la mayoría de las fibras, durante los años ochenta las telas de algodón se consolidan como el textil más apetecido por los consumidores mallorquines al significar más del $50 \%$ de la importación total. Este cambio en las pautas de consumo y su posterior consolidación queda confirmado por los datos disponibles correspondientes a otros años que no se incluyen en el Cuadro 3 y por las series creadas a partir del derecho de contrabando (Cuadro 4).

CUADRO 4. Importaciones textiles de Mallorca según el derecho de contrabando: 1707-1717 (en núrnero de piezas)

\begin{tabular}{|c|c|c|c|c|c|c|c|c|c|c|}
\hline Tela & Fibras & 1707 & 1708 & 1709 & 1710 & 1711 & 1714 & 1715 & 1716 & 1717 \\
\hline Angernics & algodón & 377 & 1.423 & 854 & 731 & 50 & 1.144 & 1.977 & 696 & 1.183 \\
\hline Brodats & a/hilo/sedn & 一 & - & 18 & 一 & - & 950 & 1.760 & 870 & 1.766 \\
\hline Cotontes & algodón & 163 & - & - & - & 22 & 291 & 1.888 & 205 & 214 \\
\hline Dimits & algodón & 90 & 34 & 169 & 77 & - & 1.895 & 467 & (3) 6 & 422 \\
\hline Fotes & lino & 107 & 130 & 145 & 188 & 8 & 491 & 1.815 & 687 & 2.423 \\
\hline Indianes & nlgadón & 2.285 & 689 & 4.387 & 2.406 & 71 & 2.165 & 3.749 & 1.798 & - \\
\hline librets & lino & 60 & - & - & - & 一 & 1.394 & 1.834 & 239 & 213 \\
\hline Itanancs & lino & 105 & - & - & - & 2 & 2.696 & 415 & 1.177 & 367 \\
\hline Otras & - & $1.71 \%$ & 380 & 452 & 528 & 483 & 1.901 & 1.368 & 555 & 1.488 \\
\hline lotal & & 4.906 & 2.650 & 6.025 & 3.930 & 636 & 12933 & 15.280 & 6.924 & $8.07 \%$ \\
\hline
\end{tabular}

Fuente: ARM, RP, 2686-2692.

A la cabeza de las telas compradas se hallan las indinnas. El grado de elaboración, la calidad, la composición y los centros productores y distribuidores ofrecen un amplio abanico de tipologías, en ocasiones necesariamente coincidentes, que se han resumido bajo el genérico al que siempre hace alusión la fuente utilizada: indiana ${ }^{37}$. En ocasiones se especifica que se trata de indianas de algodón, de color, estampadas, de hilo, de hilo estampadas, anchas, estrechas, latgas, cortas, medianas y pintadas. En otras se indica la anchura de la pie$\mathrm{za}\left(3,3^{\prime} 5,4,4 ' 5 \mathrm{y} 5\right)$ o bien el número de hilos $(20,22,24,30,34,36,40,44,48$ y 50), así como la zona de producción (Alemania, Constantinopla, Flandes, Ginebra, Holanda, Levante, Marsella, Persia y Poniente) ${ }^{38}$. Generalmente las en-

37 Aquí sólo se hace referencia a las indianas que la fuente recoge con este nombre y no se sigue, por lo tanto, la definición francesa que alude al conjunto de telas pintadas. FUKASAW', Katsumi, Tolerie et..., p. 42.

38 También se encuentran referencias de indianas a las que se añade una segunda acepción: la lama indiana se importa en 1673 (15 canas y 6 palmos) y en 1688 (15 canas). En 1679 
tradas consisten en piezas de telas de anchura y longitud desconocidas y sólo en contadas ocasiones se trata de textil confeccionado ${ }^{39}$.

La primera toma de contacto del mercado insular con las indianas se produce a mediados de los años setenta ${ }^{40}$. En 1676 los recaudadores del derecho de contrabando aplican un $10 \%$ a la entrada de una bala de indianas ${ }^{41} \mathrm{y}$ en mayo del año siguiente se descargan dos partidas, de 25 y 70 piezas, de un mismo barco procedente de Génova ${ }^{42}$. Los ocho años analizados para el período 1679-1691 certifican una etapa de estabilidad moderada con una importación media anual de unas 500 piezas, sólo rota por al avalancha de 1681 (2373 unidades). Desde 1698 hasta la entrada en vigor de la legislación que restringe su importación en $1716^{43}$, la entrada de indianería aumenta de forma acelerada y consigue duplicarse entre 1700-1704 y 1707-1716 con dos crestas que alcanzan las 4000 piezas. Su consumo, a pesar de las restricciones a determinada distribución, se mantendrá vigente durante todo el siglo XVIII ${ }^{44}$.

Aunque a mucha distancia el resto de las telas de algodón ofrece una cronología y unos ritmos importadores similares. A finales de los años ochenta irrumpen tres variedades de cotonías (amants, angemies y anquilles), las demitas, los bocassins y los ruanes, presentes en el mercado insular hasta 1716. En el caso de las sangalas su aparición se adelanta una década respecto a las anteriores para consolidarse en un volumen superior (unas 1500 piezas) hasta 1718. De esta forma y a diferencia de lo que sucediera en Barcelona, el escaso o nulo peso absoluto y relativo de las telas de algodón entre las importaciones mallor-

se halla una mención a 1 bala de drap d'indiana, mientras que las cotoninas indiana pintadas corresponden a 77 canas de 1702 y 13 piezas y 40 canas de 1703 . En 1691 se registran 4 piezas de telas de indiana pintadas. ARM, AH, 1538, 1361, 1377 y 1521.

39 Suelen ser cubremesas (43 en 1691), arquillas (1 en 1679), colchas (8 en 1677, 10 en 1699 y 4 en 1708), jubones (12 en 1679 y 2 en 1703) o pañuelos ( 35 en 1716). ARM, AH, 1361, $1370,1377,1379,1381,1521$ y 1544.

40 Los registros aduaneros de 1635-1636, 1656-1657, 1660-1661, 1662-1663, 1667-1668, 1671-1672 y 1672-1673 no registran la entrada de ninguna partida de este producto. ARM, AH, 786, 1358, 1536, 1538, 5545 y Códice 152.

41 Con anterioridad a esta fecha sólo se conoce una referencia a la entrada de 15 canas y 6 palmos de lama indiana en 1673 (equivalente a 24'633 metros). ARM, RP, 2690.

42 La primera remesa conocida del comercio regular corresponde al 13 de mayo de 1677 cuando el patrón mallorquín Esteve Gia da manifiesto de mercaderías tasadas en 7.905 libras mallorquinas. Entre ellas se encuentran 95 piezas de indianas consignadas a Pau Sager (25 piezas) y al comerciante Pau Calafat (70 piezas). ARM, AH, 1370.

43 Para el caso francés véase FuKASAwh, Katsumi, Toilerie et.., págs. 159-165 y para Espana Martín CoRra.es, Eloy, «La importación de telas...», pp. 54-56.

44 La incautación de indianas se produce en feclias tempranas. En 1722 un religioso es acusado de poseer 6 piezas y 2 retales de campo azul y flores blancas, negras y encarnadas con una longitud de 78'5 brazas (ARM, Real Acuerdo, 1722, Expediente 20). Con una legislación restrictiva anterior a la española, el sur de Francia conoce una avalancha de importaciones fraudulentas desde 1686 acelerada en las dos primeras décadas del setecientos (BourRil.LY, V.L., «La contrebande des toiles peintes en Provence au XVIIIe siècle», Annales du Midi, 27 (1914), pp. $52-75$.

1i.ipuntu, LIX/3, núm. 203 (1999) 897-924 
quinas anteriores a los años ochenta indica que la formación de este mercado, algodonero en general y del estampado en particular, se concentra en tan sólo dos décadas ${ }^{45}$.

CUADRO 5. Aprehensiones de indianas de contrabando por el resguardo de Mallorca: 1786-1798

\begin{tabular}{|c|c|c|c|c|}
\hline Año & Tipologia & Cantidad & Reos & $\begin{array}{c}\text { Número } \\
\text { aprehensio } \\
\text { nes }\end{array}$ \\
\hline \multirow[t]{3}{*}{1786} & morisca & 6 varas & desconocidos & 1 \\
\hline & extranjera & 2,5 varas & desconocidos & 1 \\
\hline & indiana & 7 varas & desconocidos & 1 \\
\hline 1787 & indiana & 151 varas & desconocidos & 5 \\
\hline \multirow[t]{2}{*}{1788} & indiana & 119 varas & 3 hombres & 7 \\
\hline & indiana & 24 varas & 1 hombre y 1 mujer & 3 \\
\hline \multirow[t]{2}{*}{1789} & rebosillo & 1 & 1 hombre & 1 \\
\hline & indiana & $445^{\prime} 5$ varas, 20 muestras, 12 tro\%o & 2 hombres y 1 mujer & 4 \\
\hline 1790 & chalecos & 1 & & \\
\hline \multirow[t]{3}{*}{1791} & blanca & 21 varas & 1 hombre & 2 \\
\hline & de algodón & 7 varas & 2 hombres & 2 \\
\hline & rebosillo & 1 & 1 mujer & 1 \\
\hline \multirow[t]{5}{*}{1792} & $\begin{array}{l}\text { indiana } \\
\text { azul }\end{array}$ & $\begin{array}{l}59 ' 5 \text { varas } \\
21 \text { varas }\end{array}$ & 1 hombre & 2 \\
\hline & de algodón & 32 varas, 5 muestras & 2 hombres y 1 mujer & 2 \\
\hline & de l'rancia & 12 '5 varas & 1 hombre & 1 \\
\hline & azul & 32 vams & desconocidos & 1 \\
\hline & fondo de color ${ }^{(1)}$ & 61 varas & & \\
\hline 1793 & neggra o blanca & 40 varas & desconocidos & 1 \\
\hline 1795 & indiana & 42 vares & 3 hombres & 1 \\
\hline $17 \% 6$ & de algodón & 3 varas & 1 marinero & 1 \\
\hline \multirow[t]{5}{*}{1797} & de algodón & 17 varas & Francesc Salom, patrón & 1 \\
\hline & pintada & 4'5 varas & 1 tejedor de lana & 1 \\
\hline & de color & 4 varas & & \\
\hline & indiana & 18 varas, 4 muestras & 3 mujeres & 3 \\
\hline & blanca & 5 varas & 1 mujer & \\
\hline \multirow[t]{4}{*}{1798} & de color & 21 varns & 2 mujeres & 2 \\
\hline & cstampada & 1 rara & hombres fugados & 1 \\
\hline & de algodón & 1 vara, 1 rctal & 1 viuda & 1 \\
\hline & $\begin{array}{l}\text { indiana } \\
\text { estampada }\end{array}$ & $\begin{array}{l}103 \text { varas } \\
54 \text { varas }\end{array}$ & 32 hombres fugados & 2 \\
\hline
\end{tabular}

Fuente: Elaboración personal. AGS, Dirección General de Rentas, Segunda Remesa, L. 1057-1069. (1) fondo color negro, morado, café o blanco.

45 Para el caso de Barcelona: FonTANA LÁzAro, Josep, «El comercio exterior...», p. 210 y MArtín Corra.cs, Eloy, «La importación de telas...., p. 51.

Highania, LIX/3, núm. 203 (1999) 897-924 


\section{La procedencia de las telas}

El permanente estado de guerra con Francia y la estructural enemistad con el imperio otomano hace que, unos por transportistas y otros por productores de telas de algodón, sean inercancías de esas procedencias las que mayoritariamente se registren por los administradores del derecho de contrabando. Desde 1676 Mallorca cuenta con una tarifa que alude a la relación entre estas plazas y el comercio algodonero y lencero ${ }^{46}$. Marsella se convertirá en el gran centro redistribuidor de las telas procedentes del levante Mediterráneo y de las que se producen en Europa ${ }^{47}$. Este control es especialmente significativo respecto a las indianas y será compartido con Génova a pricipios del siglo XVIII ${ }^{48}$. La nueva coyuntura creada por la guerra de Sucesión a raíz de las cambiantes alianzas de la isla provocan que el abastecimiento insular sea liderado por Génova en detrimento de las embarcaciones galas. Del mismo modo, se pone de manifiesto la vinculación del mercado mallorquín con el norte de Africa y el levante mediterráneo como grandes proveedores de telas. Con el final de la guetra aparece una tercera gran vía de provisión en el momento que Menorca queda bajo pabellón británico ${ }^{49}$.

46 La tarifa menciona diez artículos: telas azules de hilo ( 2 reales/pieza), tananas blancas ( 2 reales/pieza), cotoninas ( 2 reales/pieza), bordados ( 1 real/bordado), cueros de búfalo ( 3 reales/unidad), lino del fumo ( 5 reales/quintal), lino de Forfeto y de Alepo ( 3 reales/quintal), algodón hilado (16 reales/quintal), algodón fluix (3 reales/quintal) y tabaco (8-10 piezas de 8 bota). Se especifica que el resto de mercaderias tributarán un $10 \%$ de su valor. ARM, RP, 2690.

47 Mallorca establece unos sólidos vínculos con la capital provenzal a través de un intenso tráfico de aceite y telas y por la entidad de las firmas francesas representadas en la isla. La liquidación de cuentas sealizada en 1680 entre Pau de Layet y la firma Tobias Solicofre e hijo, mercaderes de Marsella, refleja la diversificación de los negocios desarrollados en Mallorca mediante su agente y la importancia otorgada a la venta de textiles. Entre otros se incluyen 6 balas de telas de Levante (3079 libras), 3 balas de telas de Alemania (?), 2 balas de renisos (1447 libras) y una partida conjunta de 1 bala de sangaletas y 1 fardico de telas de Alemania (573 libras). ARA, Protocolos notariales, R-186, f. 47.

48 La llegada de indianas a través de los puertos españoles es esporádica. Tan sólo se han detectado siete partidas en las que destaca Alicante com plataforma del mercado inglés y holandés y el escaso peso de la redistribución de Barcelona. Vía Alicante se registran 2 piezas en 1681,775 piezas de color en 1684, 13 piezas largas en 1703 y 1 pieza en 1704 . De Denia llegan 24 piezas en 1700. A través de Barcelona se canalizan 2 balas de indianas de Holanda en 1699 y 1 pieza corta en 1715 transportada por un patrón francés. ARM, $A H, 1359,1363,1367,1377$, 1378 y 1381.

49 Los nueve años registradios por el derecho de contrabando sobre el período 1707-1717 proporcionan los registros de llegada de 497 embarcaciones. El 23'5\% corresponde a Génova, seguida de los puertos españoles $(18,5 \%)$ encabezados por Barcelona y el litoral valenciano. El $155 \%$ del bloque norteafricano y levantino está capitalizado por los 34 barcos procedentes de Argel, 14 de Túnez y 11 de Orán (la lista se completa con 5 de Alejandría, 5 de Berbería, 4 de Esmirna, 3 de Tabarca y 1 de San Juan de Acre). Las presas de corso ascienden a $52(10 \% \%)$ aunque se concentran en el periodo 1707-1715. La lista se cierra con Menorca (9'4\%), Marsella desde $1714(5 \%)$ y otros puertos de menor importancia (17'5\%). ARM, RP, 2686-2692.

Hipquntu, L.IX/3, núm. 203 (1999) 897.924 


\section{La importación de fibras y su procedencia}

La estabilización al alza que durante el siglo XVII conoce la entrada de materias primas utilizadas por los sectores del cuero, metal y tintóreo encuentra en los datos del textil la confirmación de la transformación que las manufacturas insulares experimentan, especialmente, entre 1680 y 1720 . Las entradas de hierro, pieles o cueros y mordientes, tintes y astringentes no consiguen ensombrecer el peso de las fibras en el conjunto de la importación de Mallorca ${ }^{50}$.

De las cinco variedades fundamentales de materias primas textiles que importa la isla tan sólo dos merecen destacarse en este análisis. Mientras los productores vinculados a la lana, la seda y el cáñamo satisfacen la mayor parte de su consumo con la oferta local, no ocurre lo mismo con las fibras vegetales que requiere el mercado. El lino durante el siglo XVII y parte del XVIII y el algodón a lo largo del setecientos deberán comprarse en el exterior para su posterior manipulación.

CUADRO 6. Importación de lino y algodón: 1701-1718

\begin{tabular}{|c|c|c|c|c|c|c|c|c|c|c|}
\hline \multirow{2}{*}{ Años } & \multicolumn{2}{|c|}{$\begin{array}{l}\text { peso estimado } \\
\text { (libras) }\end{array}$} & \multicolumn{2}{|c|}{$\begin{array}{l}\text { valoración } \\
\text { (libras) }\end{array}$} & \multicolumn{2}{|c|}{$\begin{array}{l}\text { \% sobre materias } \\
\text { primas textiles }\end{array}$} & \multicolumn{2}{|c|}{$\begin{array}{c}\% \text { sobre materias } \\
\text { primas }\end{array}$} & \multicolumn{2}{|c|}{$\begin{array}{l}\text { \% sobre total } \\
\text { importación }\end{array}$} \\
\hline & ino & algodon & lino & algadón. & lino & algodón & lino & algadón & lino & algodón \\
\hline $1700-01$ & 68.747 & 26.955 & 13.524 & 7.508 & 58,6 & 32,5 & 28,7 & 15,9 & 6,7 & 3,7 \\
\hline $1701-02$ & 155.539 & 36.910 & 20.145 & 10.122 & 63,6 & 31,9 & 32,2 & 16,5 & 8,9 & 4,4 \\
\hline $1702-03$ & 55.728 & 7 & \pm 1.893 & 2 & 92,3 & 0,0 & 30,3 & 0,0 & 4,9 & 0,0 \\
\hline $1703-04$ & 75.900 & 1.683 & $7.64 \mathrm{~B}$ & 478 & 71,1 & 4,4 & 21,4 & 1,3 & 4,7 & 0,3 \\
\hline $1707-08$ & 52713 & 15.162 & 12. $(60)$ & 3.706 & $6.3,3$ & 18,5 & 20,3 & 5,9 & 5,9 & 1,7 \\
\hline $1715-16$ & 216.202 & 56.092 & 22.823 & 15.242 & 49,5 & 33,0 & 25,2 & 16,8 & 6,4 & 4,3 \\
\hline $1717-18$ & 46.957 & 3.455 & 11.695 & 738 & 79,8 & 5,0 & 27,2 & 1,7 & 6,1 & 0,4 \\
\hline
\end{tabular}

Fuente: Elaboración personal con datos del ARM, AH, 1368, 1377-79, 1384, 1544 y 1545. 1 libra $=407$ gramos

50 Aunque la importación media anual de tintes tiende sensiblemente a la baja (295 quintales anuales entre 1657 y 1679,272 quintales pata $1680-1700$ y 268 quintales en 1701-1718), durante la década de los ochenta se produce la sustitución de productos como la caparrosa, agalla y almagre por otros de alto consumo como ceniza, índigo y palo. Las entradas de alumbre expresan importantes variaciones anuales. Sin embargo, tras las modestas remesas de 1657 y 1661 y el vacio para el periodo 1673-1684, a partir de los años noventa se consolida como un bien de creciente aceptación: 70 quintales anuales entre 1685 y 1700 y 132 quintales entre 1701 y 1718. La evolución de las entradas de zumaque son dificiles de analizar ya que hasta 1689 se registra mayoritaria o exclusivamente en sacos y en adelante en quintales. Aún así, su consumo es regular desde 1657 para acelerarse en las dos primeras décadas del silo XVIII cuando se registran remesas anuales un $30 \%$ superiores que las de los años noventa. BibrLoNI AMENGUN., Andrés, E/ comerç exterior..., pp. 178 y 183. 
El peso específico de las fibras de algodón y, especialmente, de lino en el conjunto de las importaciones queda reflejado en el Cuadro 6 al representar más del $8 \%$ del valor medio de las compras y donde el lino tiene una presencia tres veces superior al algodón. Además, por término medio la suma de ambas fibras significa un tercio del valor de las materias primas y un $86 \%$ de las estrictamente textiles.

De esta forma, y a pesar de las notables variaciones anuales, durante las dos primeras décadas del siglo XVIII el lino y el algodón dejan un escaso margen a la entrada de exiguas partidas de cáñamo y lana, al tiempo que duplican la representatividad del conjunto de la importación de metales, tienen un valor 235 veces superior a cueros y tintes y doce veces más alto que la madera (Cuadro 7 ).

CUADRO 7. Distribución de las materias primas (porcentajes). 1701-1718

\begin{tabular}{|c|r|r|r|r|r|}
\hline Año & \multicolumn{1}{|c|}{ Textiles } & \multicolumn{1}{c|}{ Metales } & \multicolumn{1}{c|}{ Cueros } & \multicolumn{1}{c|}{ Tintes } & \multicolumn{1}{c|}{ Madera } \\
\hline $1700-01$ & 48,92 & 11,66 & 21,20 & 14,98 & 3,22 \\
$1701-02$ & 51,74 & 9,81 & 20,59 & 15,94 & 1,89 \\
$1702-03$ & 32,83 & 12,57 & 23,59 & 28,65 & 2,32 \\
$1703-04$ & 30,17 & 23,71 & 31,39 & 10,76 & 3,95 \\
$1707-08$ & 32,02 & 27,78 & 7,04 & 24,66 & 8,48 \\
$1715-16$ & 50,86 & 20,06 & 18,76 & 9,38 & 0,92 \\
$1717-18$ & 34,95 & 28,64 & 8,11 & 23,39 & 4,89 \\
\hline
\end{tabular}

Fuente: Elaboración personal según datos del ARM, AH, 1368, 1384, 1377, 1378, 1379, 1544 y 1545 .

Según los datos registrados en el Cuadro 6 y el Gráfico 1 resulta arriesgado realizar análisis a largo plazo y periodizar la evolución de los sectores lencero y algodonero. Por las ciftas disponibles existen pocas dudas de que la importación de lino es de lejos muy superior durante el siglo XVII, y especialmente entre 1680-1718, que durante el resto del setecientos. A pesar de no disponer de datos similares que permitan comparar la evolución de la producción local de lino, la incorporación creciente de lienzos en las exportaciones durante la segunda mitad del siglo XVIII indica el creciente vigor de un sector que se podría haber beneficiado de una mayor disponibilidad de materia prima en la propia isla ${ }^{51}$. Esta cronología establece que el despegue de la manufactura del lino en

51 Los datos sobre producción de lino durante los siglos XV-XVIII son escasos. Durante la segunda mitad del siglo XV su cultivo no satisface las exigencias del mercado y se importa de Alejandría, Bugía, Tatragona, Niza y, especialmente, Argel (NAQuer Bennassar, Onofre, «El comerç marítion de Mallorca a la segona meitat del segle XV", Randa 29 (1991), p. 115. Para el quinientos se tiene constancia de importantes problemas sanitarios en algunas zonas de la isla ligadas al proceso de enriado. En cuanto a la importación, la tarifa de descarga del puerto de Ciutat de Mallorca de 1577 incluye el lino procedente de Alejandría y Berberia (VAQUIBr Br:NNASSAR,

Hipanta, LJX/3, núm. 203 (1999) 897-924 
Mallorca se produce durante el periodo 1685-1718 cuando la producción de lienzos se orienta estrictamente al mercado interno en un intenso proceso en el que los productores insulares se ven arrastrados a competir con la avalancha de telas desembarcadas en la bahía palmesana ${ }^{52}$.

Esta periodización es válida para explicar la evolución del sector algodonero. La tímida pero creciente importación de fibra iniciada en el primer lustro de la década de los ochenta culmina con el aumento de las remesas registrado a principios del siglo XVIII y, especialmente, con la gran acumulación de 1716. Tras su hundimiento en las tres siguientes décadas del setecientos, los datos conocidos para la segunda mitad de la centuria siempre arrojan partidas inferiores con un tendencia claramente a la baja (Gráfico 1) ${ }^{53}$.

Onofre, Una sociedad de Antiguo Régimen. Felanitx y Mallorca en el siglo XVT, Palma 1986, vol I, pp. $156,282,287,364$ y vol. II Pp. 655-657). La práctica del cultivo persiste y a finales del siglo XVII consta en el término de la Ciutat (ARM, Protocols notarials, 3490, ff. 325-325v). Para 1715 el informe de Miquel Malonda no incluye el lino entre los cultivos más significativos de ninguna de las 2 ciudades y 35 villas a las que se refiere y sólo menciona el cáñamo para La Puebla. [UAN VIDAL, Josep, "Informe y descripción de las instituciones de gobierno, administración de justicia y de las diversas poblaciones de la isla de Mallorcas, Fontes Rerum Balearium, II (197980), pág. 282]. El descenso de la importación durante la segunda mitad del siglo XVIII se ha explicado por un aumento de la produccion insular que para 1784 sería de 235.000 libras (MANERA EliBINA, Carles, "Manufactura textil...», p. 526.

$52 \mathrm{El}$ interrogante introducido en el Gráfico 1 se debe a las dudas sobre la importación real de lino para 1754. Finalmente se ha considerado una importación de 77.312 libras tal y como se indica en MANizR ERנINA, Carles Comery $i$ capital..., p. 137 cuando se refiete a « 71.237 litures, 60 quintars $i 3$ arroves». Esta cantidad se mantiene en «Comerç, capital mercantil i manufactura tèxtil a Mallorca (1700-1830)», Randa 23 (1988), p. 45 y en «Manufactura textil...», p. 526 donde dicho autot afirma sobre el lino que «las cantidades asentadas en la aduana oscilan entre 10.000 y 80.000 libras de peson. Las dudas aparecen cuando representa gráficamente los datos y tanto en «Manufactura textil...» p. 530 como en «Comerç, capital mercantil...» pág. 61 se refiere a 131.312 libras de lino. La diferencia es de 54.000 libras.

53 La caída de la importación de algodón después de 1720 se debe a la prolibibición de su entrada en puertos españoles tras la peste de Marsella y la política seguida durante la década siguiente (MARTín CoRRAjas, Eloy, «La importación de telas...», pp. 58-59). El comercio de Mallorca con el Mediterráneo se restringe básicamente a Barcelona y la ciudad de Génova. De la región levantina y las islas sólo se admiten a cuarentena las personas (ARM, Real Audiència, Documentació Impresa, Caixa 1). En 1726 se imponen nuevos límites y se prohibie la entrada, entre otros productos, de algodón y todo lo que de él se fabrica (ARM, R.A., D.I., Caixa 2). En 1728, en prevención del contagio existente en oriente sólo se admite el algodón producido en Malta siempre que «yengan los algodones empaquetados, $y$ con una cubierta cosida, $y$ sellada, $y$ sobre esta, trayga segunda cubierta, tambien casida, $y$ sellada, $y$ con la costura encontrada á la primera, $y$ testimonio de la misma religion, y comercio de aquella isla, en que se expresse la cantidad, y calidad de que se compone cada paquete, $y$ de que dicho género es fruto propio de ella, y hapiendo diez dias de quarentenas. Poco después la Junta de Sanidad decide que Malta no dispone de «resguardo formal y riguroso, para que con ello se pueda comerciar atm con alguna cautelas. Los únicos puertos reconocidos como seguros en el Mediterráneo son: Génova, Lioma, Barcelona, Valencia, Alicante, Cartagena, Almería, Almuñécar y Málaga. En 1733 sé niega la entrada de los siguientes productos procedentes de Levante: fotes, telas rayadas de hilo y algodón, bordados, leyans, cotoninas y algodón en rama (ARM, R.A., D.I., Caixa 2). 
GRÁFICO 1. Importación de materias primas textiles $1657-1787$

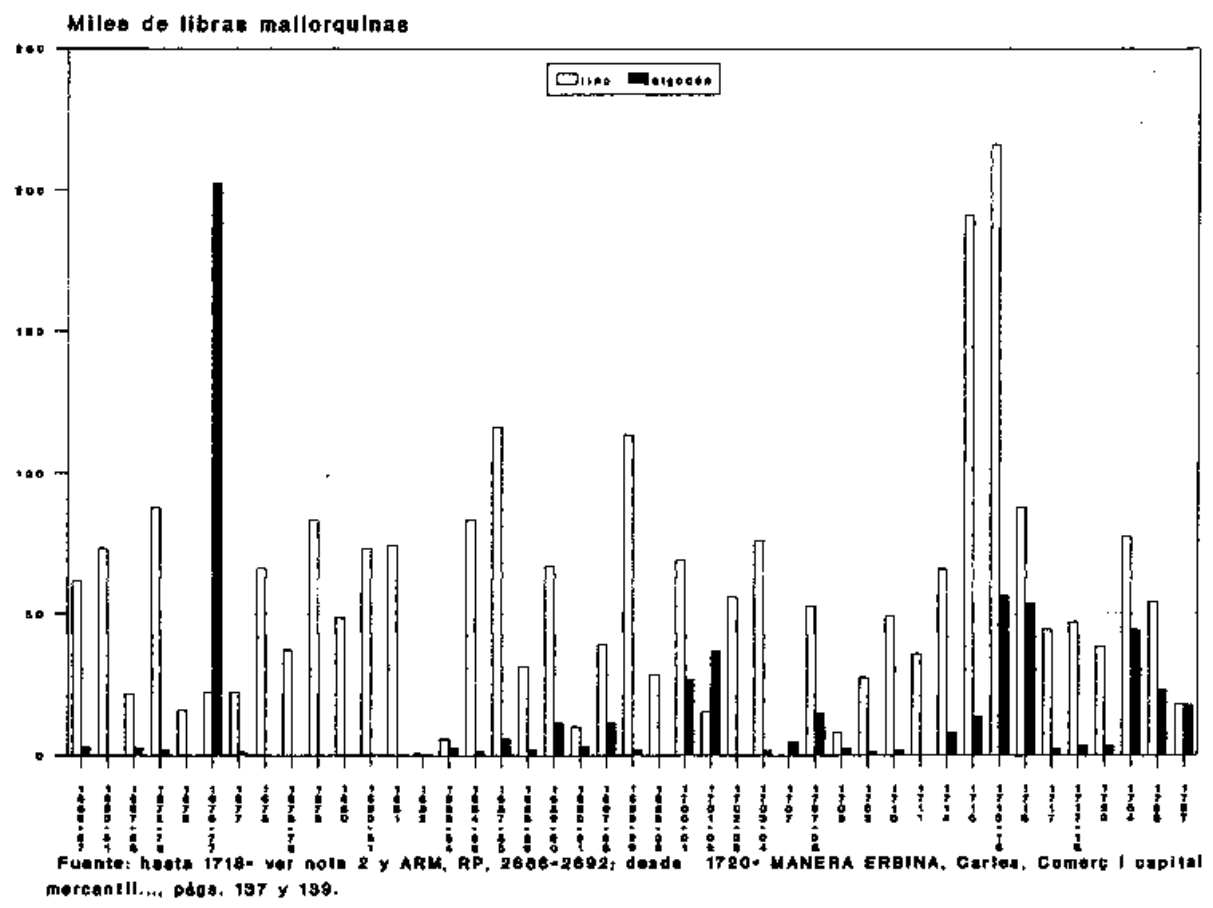

De este modo, mientras la industria lencera consigue readaptarse durante el período 1685-1718 para primero destinar la producción al mercado interno y a partir de 1720 canalizar excedentes al exterior, en el caso del algodón los intentos por impulsar una industria sustitutiva de las importaciones fracasaría y la fibra importada se utiliza fundamentalmente mezclada con el lino ${ }^{54}$.

\section{Acumulación y distribución de materia prima}

La distribución de lino, como sucede con otros productos clave de la economía insular, tiene tintes oligopólicos. El capital comercial, de nuevo, se pre-

54 MANERA ERBINA, Carles, «Manufactura textil...», p. 540 describe una cronología relativamente parecida para el sector textil del siglo XVIII con dos importantes discrepancias: considera homogéneo el período 1700-1750 caracterizado por heredar los rasgos de fines del seiscientos sin advertir ningún cambio significativo en el sector algodonero y sólo otorga un papel relevante al algodón a partir de la etapa 1750-1770 «que se introduce en la isla en cantidades destacables).

Hitpunta, I.IX/3, núm. 203 (1999) 897-924 
senta como gran protagonista de una intervención caracterizada por la actividad de un reducido grupo de mercaderes, chuetas o no, al que se debe sumar el concurso de algunos artesanos enriquecidos que generalmente no se hallan vinculados al sector textil ${ }^{55}$. El papel de la nobleza, aparentemente también insignificante, tampoco puede ser despreciado ${ }^{56}$.

CUADRO 8. Importación de lino por grupos. 1701-1718

\begin{tabular}{|r|r|r|r|r|r|r|r|r|r|r|}
\hline \multirow{2}{*}{ AÑo } & \multicolumn{5}{|c|}{ Número de cargadores } & \multicolumn{5}{c|}{$\%$} \\
\cline { 2 - 10 } & A & B & C & D & E & A & B & C & D & E \\
\hline $1700-01$ & 10 & 23 & 2 & 1 & 10 & 47,9 & 41,2 & 0,6 & 1,9 & 6,6 \\
$1701-02$ & 13 & 14 & 5 & 1 & 19 & 46,2 & 44,1 & 2,5 & 0,1 & 7,0 \\
$1702-03$ & 19 & 14 & 2 & 1 & 32 & 36,5 & 28,0 & 1,4 & 0,7 & 33,2 \\
$1703-04$ & 5 & 10 & 2 & 0 & 15 & 3,8 & 82,8 & 2,0 & 0,0 & 11,3 \\
$1707-08$ & 15 & 14 & 4 & 2 & 19 & 51,6 & 12,4 & 4,0 & 2,3 & 29,6 \\
$1715-16$ & 23 & 12 & 2 & 2 & 26 & 62,0 & 25,2 & 1,1 & 0,1 & 11,4 \\
$1717-18$ & 20 & 19 & 1 & 0 & 0 & 55,7 & 25,8 & 1,5 & 0,0 & 16,9 \\
\hline
\end{tabular}

Fuente: Elaboración personal según datos del ARM, AH, 1368, 1384, 1377, 1378, 1379, 1544 y $1545 . A=$ chuetas, $B=$ metcaderes, $C=$ artesanos, $D=$ nobles, $E=$ no identificados

La consolidación de los chuetas como intermediarios privilegiados que comparten la distribución de materia prima con otros comerciantes se hace extensiva al resto del sector textil. No en vano, sus actividades individuales y grupales abarcan el armamento corsario, el ramo del seguro y las finanzas, el comercio o determinadas actividades productivas (orfebres, terciopeleros). Sin embargo, puede que su ocupación más enraizada sea la venta, como botiguers.

55 Entre 1657 y 1700 constan 19 artesanos ligados a la importación de lino. Cinco curtidores representan el oficio más activo (Francesc Antich descarga más de 200 quintales en 1681) seguidos de 3 manteros, 2 sastres, 2 plateros, 2 carpinteros y 2 jaboneros. Cierran la lista 1 pelaire y 1 cardador. En estos años tan sólo aparece 1 tejedor de lino con una corta pero intensa actividad (en 1688 Rafel Serra importa 110 quintales por 14 quintales de 1689). De 1701 a 1718 constan 16 artesanos. Desaparecen carpinteros, plateros, sastres, pelaires y manteros y se incorporan 3 esparteros, 4 toneleros y 1 botonero. Los 4 curtidores defienden su hegemonía mientras jaboneros y cardadores mantienen un papel similat que en la etapa anterior. Un solo tejedor de lino, Joan Coll de Josep, descarga 11 quintales en 1704. Respecto al algodón la presencia de artesanos en el muelle es aún menos habitual. Hasta 1708 se limita a las discontinuas apariciones de algún curtidor $(1657,1685$ y 1690), tonelero (1688) o cordelero (1701). En 1708 y 1716 se amplia con 2 curtidores, 2 sastres, 1 tonelero, 1 sombrerero y 1 mantero.

56 El control (reab) sobre la materia prima descargada es dificil de abordar. Se consideran importadores los nombres que aparecen en los manifiestos de la aduana sin poder entrar en la especulación de quien está realmente tras una desconocida nómina de testaferros, agentes o titulares de compañias cuya composición se desconoce. 
Como el resto de los grupos socio-económicos el chueta se caracteriza por su heterogeneidad. Grandes comerciantes vinculados con el mercado exterior y pequeños vendedores al por menor conviven en un entramado de relaciones difíciles de interpretar ${ }^{57}$. Por este motivo hay que diferenciar entre la participación conjunta del grupo en el acceso a la materia prima de lino (Cuadro 8), donde convergen grandes y pequeños intermediarios, y el oligopolio ejemplificado en la trayectoria de determinados comerciantes-financieros que comparten el mercado con otros mercaderes (Cuadro 9) ${ }^{58}$.

\section{CUADRO 9. Principales importadores de lino}

\begin{tabular}{|c|c|c|c|c|c|c|}
\hline \multirow{2}{*}{ AÑo } & \multicolumn{2}{|c|}{8 principales importadores } & \multicolumn{4}{|c|}{ Principal importador } \\
\hline & Quintales & $\%$ & Nombre & Grupo & quintales & $\%$ \\
\hline $1700-01$ & 461,67 & 67,15 & Rafel Linnic Cortess & chuets & 211,58 & 30,77 \\
\hline $1701-02$ & $1.282,46$ & 82,45 & Joan Ballester & mercader & 514,32 & 33,06 \\
\hline $1702-03$ & 212,35 & 38,10 & Joan Sorn & patrón & 37,15 & 6,66 \\
\hline $1703-04$ & 684,44 & 90,17 & Antoine Danicl, francés & patrón & 574,00 & 75,62 \\
\hline $1707-08$ & 297,47 & 56,43 & Rafel Enrric Cortès & chucta & 92,35 & 17,51 \\
\hline $1715-16$ & $1.640,86$ & 75,89 & Jaume Antomì $\mathrm{P}_{i}$ icó & chucta & 560,00 & 25,90 \\
\hline $1717-18$ & 212,25 & 45,20 & Francesc Ripoll & patrón & 35,11 & 7,47 \\
\hline
\end{tabular}

Fuente: Elaboración personal según datos del ARM, AH, 1368, 1384, 1377, 1378, 1379, 1544 y 1545 .

De este modo, el análisis de los principales importadores de lino entre 1701 y 1718 (Cuadro 9) ofrece una cuádruple conclusión:

1. Las mayores concentraciones de lino coinciden con las más elevadas temesas anuales totales $(1702,1704$ y 1716$)$ cuando ocho personas asumen entre el 75 y el $90 \%$ de la importación.

2. Que el grupo de los ocho principales importadores de cada año tiene una participación muy desigual con fuertes oscilaciones entre el primero y el octavo. Generalmente cuanto mayor es la cantidad de lino que se descarga al año mayores son las diferencias en el papel de estos importadores. Son significativos los datos de 1704 cuando el primero y octavo representan respectiva-

57 Algunas de las actividades financieras de los chuetas y la evolución de su estrategia asociativa en ramo del seguro a finales del siglo XVII han sido anatizadas en PONS PONS, Jerònia, Companyies..., pp. 117-148 y 251-336. Esta autora ofrece una perspectiva a más largo plazo en E/ sector seguras en Baleares: empresas y empresarios en los siglos XIX $y$ XX, Palma 1998, especialmente pp. $7-45$.

58 Muntaner Mariano, Lleonard, Els xuetes de Mallora: Espai, Economia i Societat a finals del segle XVTI, Tesis doctoral inédita, Barcelona 1987.

Hispania, LIX/3, núm. 203 (1999) 897-924 
mente el $75^{\prime} 62 \%$ y el $1 ' 12 \%$ del total, mientras que en 1718 baja al $7 ' 47 \%$ y $4 ' 26 \%$.

3. La importancia adquirida por los transportistas como titulares 'teóricos' de la mercancía descargada (patrones Joan Sora, Antoine Daniel y Francesc Ripoll) ${ }^{59}$

4. El papel inicialmente compartido entre chuetas y otros comerciantes y más tarde hegemónico de los primeros, especialmente tras la muerte de Joan Ballester. Si a los datos contenidos en el Cuadro 9 se añaden los comerciantes que en alguna ocasión descargan más de 100 quintales de lino se obtiene una lista de diez operaciones de las que siete son protagonistas los chuetas. Pero más aún, destaca que de estas siete, tres correspondan al mismo hombre: R.E. Cortès ${ }^{0}$.

\section{CONCLUSIÓN}

Cuando se plantea si Mallorca impulsó una industria sustitutiva de las importaciones se puede menospreciar la hipótesis ante la falta de datos directos que lo demuestren o por la ausencia de estudios que se hayan interesado por el tema. Sin embargo, existen pruebas indirectas como las que proporciona el comercio que convergen en la posibilidad de plantear esta cuestión como hipótesis para futuros trabajos. Es un hecho que a partir de 1680 se multiplican las importaciones de telas de lino y algodón así como de sus fibras y productos tintóreos. También queda claro que los sectores de la seda y la lana retroceden. El interés de los pelaires y tejedores de lino en asumir el proceso de tintado indican no sólo una expansión de las funciones corporativas sino un posible cambio en la producción.

59 En 1703 Joan Sora comercializa 37'15 quintales de lino que tecibe del barco del pattón Sebastià Mulet. En 1718 Francesc Ripoll descarga una partida que ha transportado él mismo (24'05 quintales); dias antes consta una segunda remesa conducida por el patrón Antoni Mora pero cabe la posibilidad de que corresponda a un botero que tiene el mismo nombre (11'06 quintales). El caso más claro de titularidad dudosa del lino es el del francés Antoine Daniel quien en 1704 transporta desde Alejandría y descarga 357 quintales de lino del Fumo y 217 quintales de lino Forfeto. ARM, AH, 1377, 1378 y 1545.

60 Rafel Enric Cortès descarga 211 quintales en 1701, 496 en 1702 y 154 en 1716. Los otros chuetas concentran su actividad en 1716: Jaume Antoni Picó con 560 quintales, Agustí Antoni Cortès con 206 quintales, Baltasar Valentí Forteza con 170 quintales y Baltasar Joaquim Forteza con 112 quintales. (ARM, AH, 1368, 1384 y 1544). Si se exceptua la ausencia de R.E. Cortès de la lista de importadores de 1704, su control sobre el lino varia entre el 7 y el $32 \%$ del total descargado en la isla entre 1701 y 1718 . La importancia que este producto tiene en sus operaciones se manifiesta al representar un tercio de las compras que realiza en 1702 y un $45 \%$ de las de 1716. Sólo el aceite en el capítulo de las exportaciones le merecerá una atención tan significativa. En 1702 R.E. Cortès realiza 16 operaciones de exportación. En todos los casos se trata de aceite y los 23694 cuartanes (98211 litros) despachados significan un control del $6 \%$ del mercado y una presencia en el conjunto de las ventas del $5,2 \%$.

Hipania, LIX/3, núm. 203 (1999) 897-924 
El alcance de la transformación del sector lanero a principios del siglo XVIII sigue sin conocerse bien. Sin embargo, no puede descartarse la participación de dichos productores (pelaires) en la expansión del lino facilitando que, a partir de 1720, los lienzos se incorporen a los excedentes exportados. Las dudas crecen al tratarse el algodón. ¿Cuáles fueron los factores de carácter interno que condicionaron su competitividad y relegaron la fibra a la mezcla con el lino?. La historiografía local sigue sin despejar esta y otras incógnitas que afectan a los sectores clave de la economía insular del siglo XVIII. A modo de conclusión cabe preguntarse, de una vez, por qué a pesar de la magnificada diversificación productiva de la Mallorca del setecientos la isla sigue dependiendo de sus excedentes de aceite.

\section{BIBLIOGRAFÍA}

AAVV, Història de Mallorca, Palma 1980.

BLKG, Maxine, La era de las manufacturas, 1700-1820. Una sueva bistoria de la Retolución industrial británica, Batcelona 1987.

Br:RG, Maxine, «Mercados, comercio y manufactura europeaw: BriRc, Maxine (ed.), Meriados y mantufacturas en Europa, Barcelona 1995, 15-42.

BERNAI ROCA, Margarida, Els III Mesters de La Luana a Ciutat de Mallorea (ss. XIV-XVII), Palma 1995.

BERNAT ROCA, Margarida, Telers i teixidors a Mallorca. Apunts per a un estudi etnografic, Palma 1985. BIBILONI AMENGUAL, Andreu, «Reforma econòmica i 'legalització' del contraban a Mallorca, 1650-1720m: Randa 26 (1990) 85-102.

BIBILON1 AMENGUAL, Andreu, Mercaders $i$ navegants a Mallorca dxrant el segle XVII. L'oli com indicador del comery mallorqui (1650-1720), Palma 1991.

BIBILONI AMENGUAL, Andreu, El comerf exterior de Mallorca. Homes, mercats i productes d'intercanit, 1650-1720, Palma 1995.

BIBIIONI AMENGUAL, Andreu, «Tráfico y consumo textil en la Mallorca del siglo XVII»: Bolleti de la Societat Arqueologica Lulikana 51 (1995) 157-164.

BIBIJONI AMENGUAL, $\AA$., «El derecho de contrabando en las relaciones comerciales mallorquinas (1640-1720)", en C. Martínez Shaw (ed.), El Derecho y el Mar en la España Moderna, Granada 1995, págs. 31-38.

BOURrLLy, V.L., "La contrebande des toiles peintes en Provence au XVIIIe siècle», Annates $d u$ Midi, 27 (1914), pp. 52-75.

BRESC, Henri, (La draperie catalane au miroir sicilien, 1300-1460): Acta Historica et Archaeologica Medienalia 4 (1983) 107-127.

CASANOVA TODOLI, Ubaldo, La regulación contributiva del reino de Mallorca durante el sigho XVII (De la Real Pragmática de 1600 a la Concordia de 1684), Tesis doctoral inédita, Palma.

CASANOVA TODOLI, Ubaldo, «El déffit alimenticio del Reino de Mallorca a lo largo del siglo XVII y sus problemas de abastecimienton: Mayurga 21 (1985-1987).

CASANOVA TODOLl, Ubaldo, «La 'Universal Consignació' a lo largo del siglo XVII: la concordia de 1684): Estudis Balearics 26 (1987).

CiIAPMAN, S.D. y CIIASSAGNE, S., European Textile Printers in the Eighteenth Century: a study of Peel and Oberkampt, Londres 1981.

COSTA MAS, J., «La repoblació mallorquina a la Marina Alta i al seu entorn en el segle XVII\%: Trabajos de Geografia 34 (1977-1978).

CREMADES GRINAN; ROMAN CERVANTLS, Cándido, wabastecimiento de granos al Principado de Cataluña durante el asedio de Barcelona y la Guerra de Sucesión (1697-1712)n: Primer Congrés d'Història Moderna de Catalunya, Barcelona 1984.

Hipania, LIX/3, núm. 203 (1999) 897-924 
DAvIU PONS, Guillem, «La producció d'oli a Mallorca, segle XVIII. Aproximació en base a la documentació fiscaly: I Colloqui d'História Agràra, Valencia 1983, 391-410.

DHLGADO RIBAS, Josep Maria, «Pautas diferenciales en ia demanda de textiles en España e Hispanoamérica durante el siglo XVIII. Sobre la demanda interna de tejidos de algodón (1728-1778)m, Bulletin Society for Spanish and Portuguese Historical Studies (1993).

DEYA BAUZA, Miquel J., «Tradición e innovación en el sector textil mallorquin a fines del siglo XVIb: Mayurga 22 (1988).

DEYA BAUZA, Mquel J., «La industria rural textil en la Mallorca moderna: producción y formas de comercialización interion: Estudis d'Histôria Econòmica 2 (1988) 15-41.

DEYA BAUZA, Miquel J., «La comerciatización de lana en la Mallorca del siglo XV: entre el proteccionismo y el frauden: BARCELO, Maria (ed), La manufactura urbana i els menestrals (ss. XIIIXVI), LX Jomades d'Estudis Històrics Locals, Palma, 1991.

DEYA BAUZA, Miquel J, “La implantación de la 'Bolla del Redreç': un aspecto del enfrentamiento entre metcaderes y artesanos en la Mallorca del siglo XVn: Homenatje a Antoni Mut Calafell, arxiver, Palma 1993, 63-78.

DEYA BAUZA, Miquel J., La manufactura de la lana en Mallorca, 1400-1700: gremios, antesanos y comerciantes, tesis doctoral inédita, Universitat de les Illes Balears, Palma 1996.

DEYA BAUZA, Miquel J., La mantfactura de la lana en la Mallora del siglo XV, Palma 1997.

DEYA BAUZA, Miquel J., La manufactura de la llana a Mallorca (seoles XVT $i$ XVII), Palma 1998.

DOMíNGUEZ OR'JZ, Antonio, La sociedad española del siglo XVII, Madrid 1963-1970.

FONIANA LAZARO, Josep, «Sobre el comercio exterior de Batcelona en la segunda mitad del siglo XVII. Notas para una interpretación de la coyuntura catalanan: Estudios de Historia Moderna 5 (1955) 199-218.

FUKASAWA, Katsumi, Toilerie et commere du Levant d'Alep à Marseille, Paris 1987.

GIUIFrRDA, A., «Aspetti del commercio internazionale dei panni in Sicilia nella prima meta del sec. XVLn: Produzione, commercio e consumo dei panni di lana (nei secoli XII-XVIII), Florencia 1976.

JOVER, Gabriel, Desenvolupament econòmic i societat rural a Mallorca. Feudalisme, latifundi i pagesia, 1500-1800, Tesis doctoral inédita, Univ. de Girona, 1997.

JUAN VIDA., Josep, «Las crisis agrarias y la sociedad en Mallorca durante la Edad Modernas: Mayurga 16 (1976).

JUAN VIDAL, Josep, «Informe y descripción de las instituciones de gobierno, administración de justicia y de las diversas poblaciones de la isla de Mallorcas, Fontes Rerum Balearium, II (1979$80)$.

JUAN VIDAJ, Josep, «La evolución de la producción agrícola en Mallorca durante la Edad Modernan: Moneda y Crédito 145 (1980).

JUAN VIDAL, Josep, «La producción de aceite en Mallorca durante la Edad Moderna y su papel en la economía mallorquinas, $B S, A L, 832-833$ (1980).

JUAN VIDAL, Josep, «Crisis de subsistències $\mathrm{i}$ aprovisionament blader de Mallorca durant l'Edat Modernay: Randa 26 (1990).

JUAN VIDAL, Josep, El sistema de gobierno en el Reino de Mallorca (sighos XV-XVTI), Palma 1996.

MACAIRL, Pierre, Majorque et le commerce international (1400-1450 entviron), Lille 1986.

MANERA ERBINA, Carles, «Manufactura textil y comercio en Mallorca, 1700-1830», Remista de Historia Económica, 3 (1988) 39-82.

MANLiRA ERBINA, Carles, "Comerç, capital mercantil i manufactura tèxtil a Mallorca (17001830)", Randa 23 (1988).

MANERA ERBINA, Carles, Comerf $i$ capital mercantil a Mallorca, 1720-1800, Palma 1988.

MANERA ERBINA, Carles, «Resistir i créixer. Canvi econòmic i classes socials a la Mallorca del segle XVIIn: Randa 26 (1990).

MANERA ERBINA, Carles, «Desarrollo económico y actitudes empresariales en la Mallorca contemporánea, 1730-1930. Rasgos económicos de una sociedad pre-turística), Documento de Trabajo 9509. Fundación Empresa Pública, Madrid 1995.

MART'ín CORJAL_Es, Eloy, «Consumo de algodón en la Cataluña de la segunda mitad del siglo XVII y nacimiento de la indianerias, VI Simposio de Historia Económica, Bellaterra-Barcelona 1992. 
MARTÍN CORRNLlLS, Eloy, «La importación de telas de algodón levantino y los inicios del estampado en Cataluñas: Revista de Historia Industrial 6 (1994) 47-74.

MUNFANER MARIANO, Lleonard, Els xuetes de Mallorca: Espat, Economia i Societat a finals del segle $X V T$, Tesis doctoral inédita, Barcelona 1987.

NADAL OLLER, Jordi, La población española (siglos XVI a XX), Barcelona 1984.

PONS PONS, Jerònia, Companyies $i$ mercat assegurador a Mallorca (1650-1715), Palma 1994 (tesis doctoral parcialmente inédita).

PONS PONS, Jerònia, Companyies $i$ mercat assegurador a Mallorca (1650-1715), Palma 1996.

PONS PONS, Jerònia, El sector seguros en Baleares: empresas y empresarios en los siglos XIX y XX, Palma 1998.

QUEIGLAS, Bartolomé, Los gremios de Mallorta, siglos XIII al XIX, Palma 1980.

ROURA, Lluis, L'Antic Règim a Mallorca. Abast de la conmoció dels anys 1808-1814), Palma 1985.

SÁNCHEZZ SUÁRLŹ, Alejandro, «La era de la manufactura algodonera en Barcelona, 1736-1839\%: Estudios de Historia Social 48-49 (1989) 65-113.

SÁNCHEZ SUÁREZ, Alejandro, «La indianería catalana: ¿mito o realidad’n: Revista de Historia Industrial 1 (1992) 213-232.

SANIAMARI A, Alvaro, Nueva Planta de Gobierno de Mallorca. Enfiteusis urbana y real cabrevación, Palma 1989.

SAVARY DES BRUSLONS, Jacques, Dictionaire universel de commerce, Paris 1728.

SEVIL ANO COLOM, Francisco, (cArtesanía textil de la lana mallorquina (siglos XIV y XV) n: Produzione, commercio e consumo dei panni di lana (s. XII-XVIII), Florencia 1976.

SUAU PUIG, Jaume, «Demografia rural mallorquina del segle XVIII»: Magurga 16 (1976).

T'HOMSON, James, La industria d'indianes a la Barcelona del segle XVTII, Barcelona 1990.

THOMSON, James, Els origens de la industrialitqació a Catalumya. El cotó a Barcelona (1728-1832), Barcelona 1994.

THOMSON, James, «Intervención del Estado en la industria catalana de estampado de telas en el siglo XVIIIn: BERG, Maxine (ed.), Mercados y manufacturas en Europa, Barcelona 1995, 74 110 .

VAQUER BENNASSAR, Onofre, Una sociedad de Antiguo Régimen. Felanitx y Mallorca en el siglo XVT, Palma 1986.

VAQUER BENNASSAR, Onofre, (Les manufactures mallorquines de teixits i de pells a la segona meitat del segle XV: importacions i exportacionss: BARCliJO, Maria (ed), La manufactura urbana i els menestrals (ss. XIII-XVI), IX Jornades d'Estudis Historics Locals, Palma 1991.

VAQUER BENNASSAR, Onofre, "El comerç maritim de Mallorca a la segona meitat del segle XV), Randa, 29 (1991)

Hìpontiu, LIX/3, núm. 203 (1999) 897-924 